\title{
Riskiness Choice and Endogenous Productivity Dispersion over the Business Cycle*
}

\author{
Can $\operatorname{Tian}^{\dagger}$ \\ University of Pennsylvania
}

First Version: May 30, 2011

This Version: June 9, 2012

\begin{abstract}
Cross-sectional productivity dispersion is countercyclical, at the plant level and at the firm level. I incorporate a firm's project choice decision into a firm dynamics model with business cycle features to explain this empirical finding both qualitatively and quantitatively. In particular, all projects available have the same expected flow return and differ from one another only in the riskiness level. The endogenous option of exiting the market and limited funding for new investment jointly play an important role in motivating firms' risk-taking behavior. The model predicts that relatively small firms are more likely to take risk and that the cross-sectional productivity dispersion, measured as the variance/standard deviation of firm-level profitability, is larger in recessions.
\end{abstract}

Keywords: Countercyclical Productivity Dispersion, Business Cycles, Firm Dynamics.

JEL Classification Codes: E32, L11, L25

*This is a revised version of my third year paper at UPenn. I am deeply indebted to Dirk Krueger for insightful advice and constant encouragement. I am grateful to Ufuk Akcigit, Harold Cole and Jeremy Greenwood for great comments. I also thank Rudiger Bachmann, Jie Cai, Aubhik Khan, Fei Li, Min Ouyang, Pengfei Wang, Yi Wen, Laura Wu, Xiaodong Zhu and participants at the 2011 North America Summer Meeting of the Econometric Society, 2011 Asian Meeting of the Econometric Society, and 2011 Tsinghua Workshop in Macroeconomics for Young Economists. All errors are mine.

†333 McNeil Building, 3718 Locust Walk, Philadelphia, PA 19104-6297, USA. (Email: tiancan@sas.upenn.edu) 


\section{Introduction}

Cross-sectional productivity dispersion tends to rise in bad times. This is the case for productivity at the plant, firm, and industry level. Recently, this phenomenon has attracted growing attention from economists, with much new evidences from micro-level data sets. ${ }^{1}$ However, the significantly negative correlation between uncertainty and aggregate economic conditions is often treated as a calibration discipline, and not much work has been done to explain it.

In this paper, I provide a possible mechanism through which the worsened aggregate economic conditions lead to an increase in the measured dispersion in firm/plant-level productivity. ${ }^{2}$ The model employed is close to the standard industry dynamics model with firm entry and exit built in the seminal work of Hopenhayn (1992), with aggregate fluctuations in "technology shocks" as the driving force of business cycles. Meanwhile, it differs from the standard model in that in each period, after observing the aggregate "technology shock realization," a staying firm has the option to adopt a risky project, in addition to a standard safe project whose productivity realization is determined by the aggregate state. Given the same capital input, the output and productivity associated with the risky project is a mean-preserving spread of the safe project's output and productivity. Although firms are risk neutral and the risky project does not give a higher flow payoff, there is a positive fraction of firms that strictly prefer to take the risk. This is because the option of exit provides a lower bound for a firm's continuation value as a function of working capital and creates a local convexity in it. Therefore, firms in this region have the incentive to randomize over their future values by choosing the risky project, and when the uncertain productivity is realized, dispersion arises. This setup resembles Vereshchagina and Hopenhayn's (2009) model of occupational choice. In bad times, this risky region gets larger and the fraction of risky firms rises. Consequently, the average or aggregate riskiness in firms' production increases, and so does the realized productivity dispersion. Despite the fact that the model is fairly standard with one little twist, it is capable of generating productivity dispersion negatively correlated with the aggregate state of the economy, with a correlation coefficient quantitatively in line with the data.

This model's mechanism is strongly motivated by empirical findings. It has features and implications that mirror the following micro-observations: (1) business cycle indicators lead the change in productivity dispersion; and (2) in recessions, more firms become risky and the exit

\footnotetext{
${ }^{1}$ Examples are Higson, Holly and Kattuman (2002), Higson, Holly, Kattuman and Platis (2004), Bloom (2009), Bloom, Floetotto and Jaimovich (2010), Bachmann and Bayer (2011), Arellano, Bai and Kehoe (2009), Bachmann, Elstner and Sims (2011), Chugh (2010), Kehrig (2011), to name a few.

${ }^{2}$ This paper is not on firm theory. In what follows, the difference between a firm and a plant is not distinguished. The optimal number of plants/establishments a firm should have, although an interesting and important question, is not the focus.
} 
rate is therefore countercyclical; (3) new firms are relatively small and small firms have a low survival rate; (4) small and/or young firms tend to bear more risk and/or show larger productivity dispersion.

The first two points involve the cyclical change. The increase in measured cross-sectional dispersion of plant- and/or firm-level productivity lags the worsened business cycle indicators, for example, the GDP growth rate, as shown in Bachmann, Elstner and Sims (2011) and Kehrig (2011) among others. A similar response is observed in the stock market. The last point relates to the key feature of the model. Although, unfortunately, I do not have direct observations from the data, there is indirect evidence that implies that there is a larger fraction of risky firms in recessions, consisting mainly of small firms. The exit rate rises in bad times. The findings on the relation between firm size and exit rate show that small firms and establishments drive the negative correlation between the exit rate and business cycles. This indicates that small firms are more sensitive to the cyclical change, as the model predicts. The increased exit rate in bad times is shown in papers such as Campbell (1998) and Jaimovich and Floetotto (2008) and is discussed in Section 2. Perhaps more direct evidence is found in the cyclical pattern of price dispersion recently documented in Bachmann and Moscarini (2011) and Berger and Vavra (2011). Cross-sectional dispersion in price changes is countercyclical, both within and across sectors. Meanwhile, the dispersion is positively correlated with the frequency of adjustments, which is also countercyclical. The higher adjustment frequency in bad times can be interpreted as a result of firms doing more frequent risky pricing experiments due to lower experimentation cost, as in Bachmann and Moscarini (2011).

The latter two points are closely related, as the exit hazard is a special form of firm-level risk. The relation between firm size and dynamics is well established and can be traced back to, for example, Dunne, Roberts, and Samuelson (1988). This is discussed further in Section 2. The findings on firm size and riskiness mainly come from two directions. First, it is well established in the entrepreneurship literature that entrepreneurs, especially poorer ones, bear a substantial amount of risk and tend to hold largely undiversified assets by investing heavily in their own firms, despite little or no premium in doing so. The risk here is interpreted as either the dispersion in small firm owners' personal income or the dispersion in return to private equity. At the same time, privately owned businesses are, on average, smaller in scale, measured in terms of either capital stock, number of employees, or output. ${ }^{3}$ The second stream of empirical findings, more relevant to my work, regards the productivity and firm size differential. Gertler and Gilchrist (1994), using the Quarterly Financial Report for Manufacturing Corporations, find that smaller firms exhibit

\footnotetext{
${ }^{3}$ Examples of work in this direction are Hamilton (2000), Moskowitz and Vissing-Jorgensen (2002), and Herranz, Krasa and Villamil (2009). See Quadrini (2009) for a detailed review.
} 
a higher standard deviation in sales growth rates than larger ones do. Dhawan (2001) looks at publicly traded firms in Compustat and finds that small firms have a higher failure rate and a larger standard deviation in profit rate, while, conditional on surviving, small firms show a higher average profit rate. The superior profitability in small firms is reducd if profits are adjusted according to the failure rates. Here, Dhawan defines the profit rate as operating income per unit of capital, and he defines the firm-level riskiness or volatility as the variance in the random realizations of production. Using his definitions, my model generates the same pattern of profit rate and riskiness differential by size. There is also evidence from outside the U.S. For example, using a firm-level German data set, USTAN, that covers the majority of German industries, Bachmann and Bayer (2011) find decreasing productivity risk in firm size, where the risk is measured as the average cross-sectional standard deviation in log-differences in firm-level Solow residuals.

The goal of this paper is to complement existing theories on what causes the negative correlation between business cycles and cross-sectional productivity dispersion. It is true that, if measured uncertainty and aggregate economic conditions are correlated, the cause can be from either direction. The real option literature that aims to explain such countercyclicality suggests the opposite direction for a causal relationship, from increased uncertainty to decline in aggregate economic activity. An influential paper in this area is Bloom (2009), which was later generalized by Bloom et al. (2010). Bloom shows that increased uncertainty, through the channel of adjustment costs to capital and labor, leads to a larger option value of waiting and a pause in investment and employment. A sizable drop in aggregate economic activity occurs because of this "wait-and-see" effect. The time-varying uncertainty is twofold in his model: (1) the time series standard deviation of productivity can be either high or low, evolving as a Markov process, and (2) the one-step-ahead conditional variance of this Markov process depends on current realization. However, Bachmann and Bayer (2011) and Bachmann, Elstner and Sims (2011) show that there is little evidence of sizable "wait-and-see" effects in the data. In addition, the process of entry and exit is neglected. Arellano, Bai and Kehoe (2009) do consider the entry and exit dynamics that interact with financial constraints, but, again, the causal direction is from a time series uncertainty shock to a sizable response in aggregate variables.

It is important to note that the importance of the uncertainty shock is not denied in this paper, and the inverted causality may still be true. But there is an issue regarding measuring uncertainty, which relates to the lead-lag relationship between uncertainty and cycles. Time series variances of major business condition indicators are often interpreted as uncertainty. In addition, a parallel family of uncertainty measures concerns the realized cross-sectional dispersion in micro-level performance, which includes, among other things, the cross-sectional variance in measured firm-level total factor productivities, levels or growth rates, and sales growth rates. 
However, realized cross-sectional dispersion is only a proxy for uncertainty. Besides, increased micro-level cross-sectional dispersion tends to lag recessions. This suggests a possible causality from an aggregate economic state to measured uncertainty, in particular, cross-sectional dispersion in productivities. This paper looks at this interesting issue from an angle different from the one adopted by the aforementioned literature.

The other paper that entertains the same causal direction as mine is Bachmann and Moscarini (2011). They build a model in which firms need to run costly experimentation and hence learn about their own market powers. As a result of lower experimentation costs, the dispersion of productivity measured in sales is larger during recessions due to more experiments being conducted. My model shares a similar feature with theirs, in that the option of exiting promotes the risky performance of firms, while the rest of the mechanism is very different. At the same time, my model differs from theirs by predicting that smaller firms are the major contributors to productivity dispersion and entry/exit dynamics.

The rest of the paper is organized as follows. Section 2 describes the stylized facts on the cyclical dispersion of productivity, firm size distribution, and dynamics. Section 3 contains a simple three-period model that illustrates the mechanism and shows preliminary results. Section 4 takes the simple model to an infinite horizon. Section 5 concludes.

\section{Empirical Facts}

Cyclical Productivity Dispersion. Eisfeldt and Rampini (2006) use data from Compustat and find countercyclical movement of dispersion in Tobin's $q$. At the same time, they show a similar pattern for dispersion of total factor productivity growth rates at the four-digit SIC level, with a correlation of -0.465 . Bloom (2009) shows that U.S. stock market volatility, as measured by the VXO index, is positively correlated with the cross-sectional standard deviations of firm profit growth, firm stock return, and industrial TFP growth at the four-digit SIC level, but its correlation with industrial production is significantly negative. Moreover, Bloom, Floetotto and Jaimovich (2010) take an even closer look at this issue and examine the Census of Manufactures. They find that various measures of uncertainty are significantly countercyclical at all establishment, firm, industry, and aggregate levels. Bachmann and Bayer (2011) use a long panel of German firm-level micro-data that covers all single-digit industries to show that the correlation between dispersion in growth rates of firm-level TFP, sale, and value added and economic performance is significantly negative. This pattern is maintained in subsamples divided by sector and by size. Although taken from a different economy, their USTAN data set has the clear advantage in coverage. Moreover, by looking at different size quantiles, they document that average time series productivity dispersion 
in smaller firms tends to be larger than in bigger firms. Chugh (2010) explores the profitability series constructed by Cooper and Haltiwanger (2006) from the Longitudinal Research Database and calculates the cyclical correlation between average productivity and the dispersion of profitability to be -0.97 . However, the sample is of relatively short length, covering only 1977-1988, a period that exhibits an unusually large degree of opposite movement. Kehrig (2011) focuses more on the dispersion of productivity levels rather than profit rates. He looks at the establishment-level data of the U.S. manufacturing sector that consists of the Annual Survey of Manufactures, the Census of Manufactures, the Plant Capacity Utilization Survey, and the Longitudinal Business Database. Although the manufacturing sector as a whole shows a countercyclical dispersion in establishment-level TFP, the durable goods industries show stronger cyclicality and it is the firms in the bottom quantile of the productivity distribution that drive the dispersion dynamics.

In this paper, I study how the aggregate economic state affects the dispersion in micro-level productivity. To link my model to data, ideally, the aggregate state is the average productivity measured as the cross-sectional average of plant-level TFP, and the dispersion is then the variance or inter-quantile range of plant-level TFP. Lacking the plant-level data, I use industry data at the four-digit SIC level to approximate the desired measures. The paper is silent on the validity of this approximation, but Bloom et al. (2010) show that the countercyclical patterns of productivity dispersion are similar at the plant, firm, and industry levels.

The upper panel of Figure 1 shows the co-movement of different business cycle indicators. In particular, I claim that the average TFP is a valid aggregate state indicator for the manufacturing sector. The correlation coefficient between average TFP (HP filtered) and sectoral output (HP filtered) is 0.86 with a p-value of scale $10^{-9}$. The average TFP corresponds to the cyclical indicator used throughout the model, and the fluctuation in TFP represents a technology or productivity shock, which drives the dynamics of the model economy. Following Eisfeldt and Rampini (2006) and Bloom (2009), I use dispersion in the cross-sectional distribution of the TFP growth rate at the four-digit SIC level to approximate that at the individual level, without arguing the validity of the approximation. Note that the desired distribution is that of the levels of TFP instead of growth rates. The result is the lower panel of Figure 1, which illustrates the countercyclical movement of the variance in TFP. ${ }^{4}$ The precise correlation coefficients for the U.S. manufacturing sector are documented in detail in both Bloom, Floetotto and Jaimovich (2010) and Kehrig (2011) and are summarized in Table 1 together with my own calculations.

\footnotetext{
${ }^{4}$ I obtain data from the same sources as the aforementioned two papers, yet with more recent data up to 2005. I get the same significantly negative correlations as in those two papers if I use only the same range of data as they do. However, if I include the updated data as shown in Figure 1, I find a negative correlation that is not significant and is much smaller in absolute scale, which is less than 0.11 .
} 

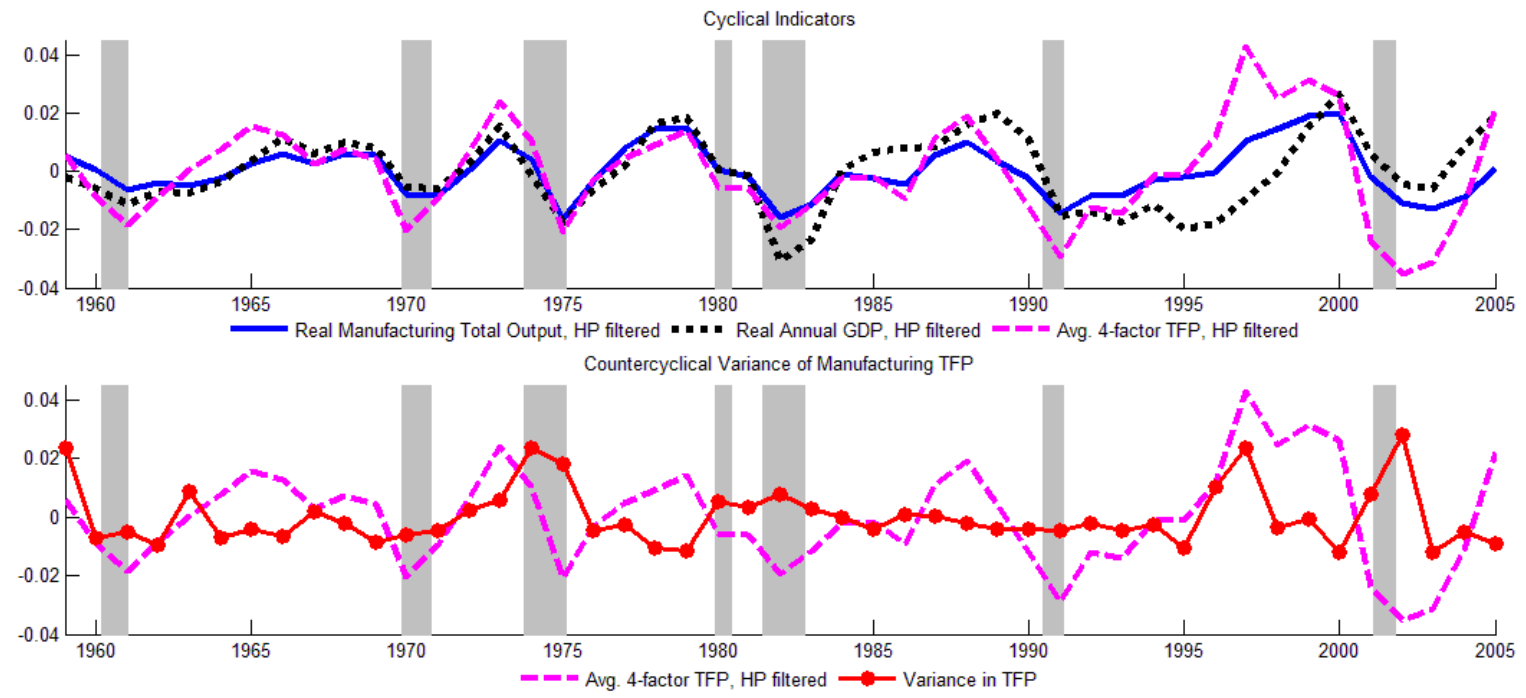

Figure 1: Cyclical Indicators and Variances in TFP. The upper panel plots different cyclical indicators, Real GDP (dotted line), Real total manufacturing output (solid line), Average TFP across industries at the 4-digit SIC level (dashed line). The lower panel shows the cyclical behavior of TFP dispersion measured as the variance (solid line with dots), together with Average TFP (dashed line). All series are HP-filtered. The shaded bars indicate official NBER recessions. Real GDP data are from FRED; TFP series are from MIPD, as is Manufacturing output measured as Real Total Shipments. 
Table 1. Correlations Between Dispersion and Cyclical Indicators ${ }^{5}$

\begin{tabular}{|c|c|c|c|c|}
\hline & For US Manufacturing Sector & GDP Growth & GDP HP Res. & Avg. $\triangle \mathrm{TFP}$ \\
\hline \multicolumn{5}{|c|}{ Kehrig (2011) } \\
\hline (1) & $\begin{array}{l}\text { Estab. TFP, Std. Dev. } \\
\text { (Durables, HP Residual) }\end{array}$ & -0.420 & -0.528 & - \\
\hline$(2)$ & $\begin{array}{l}\text { Estab. TFP, Std. Dev. } \\
\text { (Non-durables, HP Residual) }\end{array}$ & -0.172 & - & - \\
\hline \multicolumn{5}{|c|}{ Bloom et. al. (2010) } \\
\hline (3) & Estab. Output Growth, IQR & -0.364 & - & - \\
\hline (4) & Estab. TFP Growth, Std. Dev. & -0.273 & - & - \\
\hline (5) & Firm Sales Growth, IQR & -0.265 & - & - \\
\hline (6) & Firm Stock Returns, IQR & -0.339 & - & - \\
\hline \multicolumn{5}{|c|}{ Calculated from NBER-CES MIPD } \\
\hline (7) & Ind. TFP Growth, IQR & $-0.502(0.000)$ & $-0.298(0.021)$ & $-0.184(0.108)$ \\
\hline (8) & Ind. TFP Growth, Std. Dev. & $-0.262(0.038)$ & $-0.241(0.051)$ & $-0.129(0.194)$ \\
\hline (9) & Ind. TFP Growth, Var. & $-0.249(0.046)$ & $-0.245(0.048)$ & $-0.123(0.206)$ \\
\hline
\end{tabular}

Due to the limitations of the data, I use dispersion measures for the TFP growth rate instead of the TFP level. The corresponding cyclical indicators are then the GDP growth rate, the sectoral output growth rate, and the average TFP growth rate. To be comparable to other works, I include only the GDP growth rate and GDP HP residuals in Table 1.

Firm Dynamics. One important cyclical feature of firm dynamics that motivates this paper is that the exit rate moves countercyclically. This phenomenon is well documented in Campbell (1998) who uses ASM data between the second quarter of 1972 and the last quarter of 1988. In addition, Jaimovich and Floetotto (2008) assemble a new annual data set from 1956 to 1996 at the firm level across a broader range of industries and find that despite the difference in numbers,

${ }^{5}$ The first column of results shows the correlation coefficients ( $p$-value) for real GDP growth rate, the second for residuals of HP-filtered real GDP, and the last for the weighted average TFP growth rate in the manufacturing sector. Rows (1) and (2) are taken from Tables 3 and 4 in Kehrig (2011), in which the micro-level data sources are mainly ASM/CM/LBD, continuously covering the period of 1972-2005 at an annual frequency. Rows (3) to (6) are from Table 1 in Bloom, Floetotto and Jaimovich (2010). Establishment-level data are also from ASM/CM/LBD, 1972-2006, while the firm-level infomation is from Compustat at quarterly frequency, 1967:II-2008:III for sales growth and 1969:I-2010:III for stock returns. Rows (7) to (9) are TFP dispersions across industries at the fourdigit SIC level and the NBER-CES Manufacturing Industry Productivity Database is the source, covering 1959-2005 at an annual frequency. Except for IQR, all other moments of industrial TFP growth are weighted by the real value of total shipments. Numbers in parentheses are one-sided $p$-values under the null of non-negative correlation. 
the exit rates of all examined industries are countercyclical. To illustrate firm dynamics over time, I obtain annual data from 1977 to 2009 in Business Dynamics Statistics (BDS) at CES, a data set that recently became publicly available. To be consistent with micro-level evidence on countercyclical dispersion, I look only at establishments in the manufacturing sector. ${ }^{6}$

Table 2 summarizes the establishment entry and exit rates by firm size. ${ }^{7}$ A firm is classified as small if it has fewer than 50 registered employees. This is again not ideal, but subject to data availability. The preferred size classification is by capital stock. A more detailed illustration of entry and exit rates by year and by establishment size can be found in the Appendix.

Table 2. Entry and Exit Rates in Manufacturing Sector ${ }^{8}$

For U.S. Manufacturing Sector 1977-2009

\begin{tabular}{|c|c|c|c|c|}
\hline & & Total & Large & Small \\
\hline (1) & Avg. Entry Rate (\%) & 9.36 & 5.18 & 31.18 \\
\hline$(2)$ & Avg. Exit Rate (\%) & 9.28 & 6.00 & 30.06 \\
\hline$(3)$ & Std. Dev. $\left(\right.$ Entry $\left.^{H P}\right)(\%)$ & 0.52 & 0.64 & 1.85 \\
\hline$(4)$ & Std. Dev. $\left(\right.$ Exit $\left.^{H P}\right)(\%)$ & 0.67 & 0.90 & 1.56 \\
\hline$(5)$ & Corr $\left(\right.$ Entry $\left.^{H P},(\text { Avg. TFP })^{H P}\right)$ & $0.20(0.29)$ & $0.19(0.33)$ & $0.21(0.29)$ \\
\hline (6) & $\operatorname{Corr}\left(\operatorname{Exit}^{H P},(\text { Avg. TFP })^{H P}\right)$ & $-0.26(0.17)$ & $-0.17(0.37)$ & $-0.23(0.24)$ \\
\hline$\left(5^{\prime}\right)$ & $\operatorname{Corr}(\Delta$ Entry, Avg. $\Delta \mathrm{TFP})$ & $0.22(0.26)$ & $0.13(0.51)$ & $0.31(0.11)$ \\
\hline$\left(6^{\prime}\right)$ & $\operatorname{Corr}(\Delta$ Exit, Avg. $\Delta \mathrm{TFP})$ & $-0.10(0.62)$ & $0.06(0.76)$ & $-0.06(0.73)$ \\
\hline
\end{tabular}

\footnotetext{
${ }^{6} \mathrm{~A}$ noteworthy issue here is how to define an entering establishment and an exiting one. According to the official overview of the BDS data set, "An establishment opening or entrant is an establishment with positive employment in the current year and zero employment in the prior year. An establishment closing or exit[ing] is an establishment with zero employment in the current year and positive employment in the prior year. The vast majority of establishment openings are true greenfield entrants. Similarly, the vast majority of establishment closings are true establishment exits (i.e., operations ceased at this physical location). However, there are a small number of establishments that temporarily shutdown (i.e., have a year with zero employment) and these are counted in the establishment openings and closings." Therefore, an inevitable caveat is that although of relatively small number, an "idling" establishment can show up in the data first as an exiting one, and then as an entrant, for potentially many times. However, one clear advantage especially over firm-level data is that mergers and acquisitions are not reasons for disappearing units. Therefore, I can safely assume that exiting establishments suffer from low realizations of productivity.

${ }^{7}$ The entry and exit rates are indeed calculated using the numbers of newborn establishments, closed establishments, and existing establishments. However, the size is classified using the number of employees in a firm, instead of an establishment. One can only argue that large firms tend to own large establishments, and therefore large establishments exhibit similar dynamics to the ones owned by large firms. Otherwise, it is not clear whether this is a valid approximation.

${ }^{8}$ The data source is still BDS. The binary grouping rule in size can be found in the caption for Figure 2. In Rows
} 


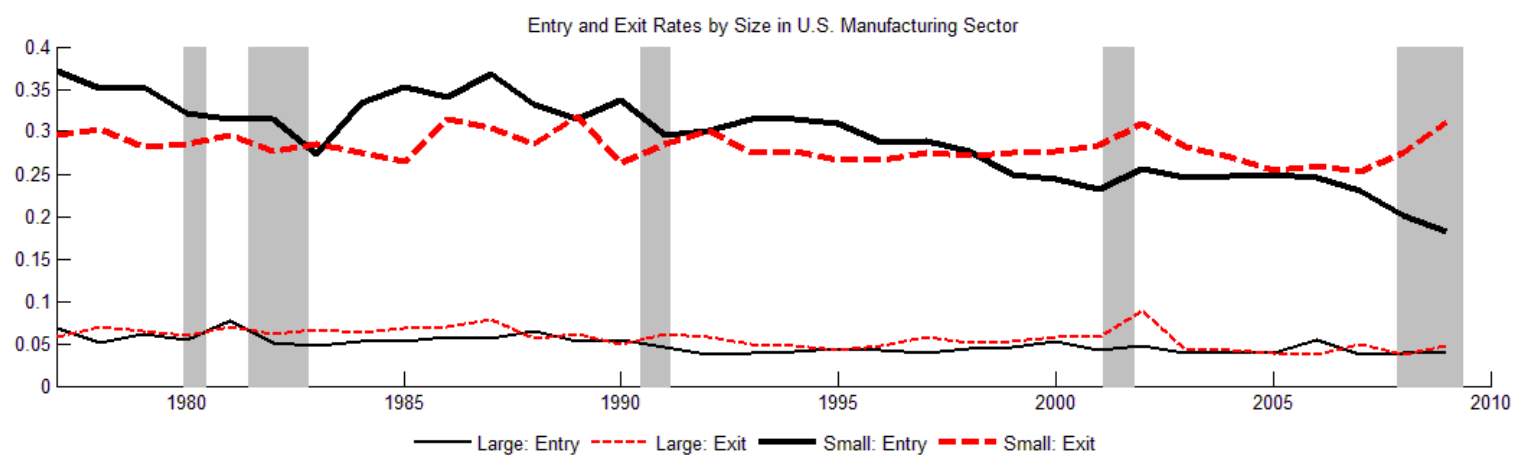

Figure 2: Cyclical Behavior of Entry and Exit in Manufacturing Sector by Size. A small firm is classified as one with fewer than 50 registered employees, and a large one with at least 50. This figure shows the original series of entry (solid lines) and exit (dashed lines) rates by size. The two thinner lines at the bottom are for large firms, and the two thicker ones are for small firms. Data on entry and exit rates are from BDS of CES.

Comparing establishment dynamics in small firms to those of large ones, they are of a much larger scale, more volatile, and more cyclical. Therefore, in the quantitative model, I focus only on the dynamics in small firms and treat the entry and exit of large firms mainly as exogenous, and they happen only with small probability.

The model I build in the following sections tries to explain the negative correlation between average productivity and cross-sectional productivity dispersion. The main mechanism emphasizes the different behavior between small and large firms, which leads to observed differences in their entry and exit dynamics.

\section{A Simple Model}

To highlight the mechanism, I start from a simplified and tractable three-period version of the full model. I remove some features of the working model that are not as crucial and focus only on the incumbents' problem. The main idea is that the option to exit promotes risk taking of small firms by creating a local non-concavity in a firm's continuation value function, which in turn

(1) and (2), the numbers are simple time series averages. Rows (3) and (4) are time series standard deviations for HP residuals. Rows (5) to (6) are correlations for HP residuals, and Rows (7) and (8) are for changes. Numbers in parenthesis are p-values. I choose to compute correlation coefficients in this way instead of using original entry/exit rates because there is a declining trend in both series. This is an interesting observation for its own sake, but this paper is silent on it. 
generates a non-degenerate dispersion in productivity. Moreover, as is shown in the comparative statics analysis, such dispersion becomes larger in bad times, due to a larger fraction of risk-taking firms. The same mechanism drives the infinite horizon model as well.

\subsection{Setup}

There are 3 periods, $t=0,1,2$. There is a continuum of risk-neutral firm owners, each of whom owns a firm with different levels of initial resources $w_{0} \in[0, \bar{w}]$. Assume that there is only one final good and each firm has only one plant that produces this good. The c.d.f. of owners' initial endowment of the single good is given as $G\left(w_{0}\right)$. At period 0 , initial wealth $w_{0}$ can be divided into investment $k_{0}$ for future payoff and immediate consumption $w_{0}-k_{0}$. If an owner decides to invest $k_{0}$, then she will get $w_{1}=F(Z, k)$ as period 1 wealth, where

$$
F(Z, k)=Z k^{\alpha}, 0<\alpha<1
$$

and $Z$ represents the realized productivity of the project the firm owner chooses after the investment decision. A production project is associated with a project. Assume that production requires full attention of the firm's owner and uses the full capacity of the plant; hence, a firm cannot undertake multiple production projects simultaneously. An owner can choose one and only one out of two available projects: a safe one and a risky one, differing in the riskiness and realizations of productivity. For the safe project, $Z=A$ for sure, while for the risky one, with probability $p \in(0,1), Z=\bar{z}>A$, and with probability $1-p, Z=\underline{z}=0$. Both projects give the same expected value of $Z$, that is, $p \bar{z}+(1-p) 0=A .^{9}$ The risky project has a variance in productivity as a function of $p$ and $\bar{z}, \sigma^{2}(p, \bar{z})=p(1-p) \bar{z}^{2}$. As a result of the linearity of $F(Z, k)$ in $Z$, the expected flow output of the risky project is the same as the safe one. Under this setup, $A$ corresponds to the average establishment-level productivity measured as TFP in the data and plays the role of economic condition indicator (or cyclical indicator in the full model); the riskiness of the risky project represents the risk at the establishment level, while its aggregated counterpart measures the dispersion in productivity.

\subsection{Analysis}

At period 1, after the uncertainty in $Z$ is realized, the agent can decide whether to close her firm, exit the industry and get an outside option value $V^{0}$, or stay. Conditional on staying, she

\footnotetext{
${ }^{9}$ For tractability, I assume only one type of risky technology and binary possible realization of it. In fact, a risky technology can be represented by a random variable $Z$ with any distribution that is a mean-preserving spread of $A$.
} 


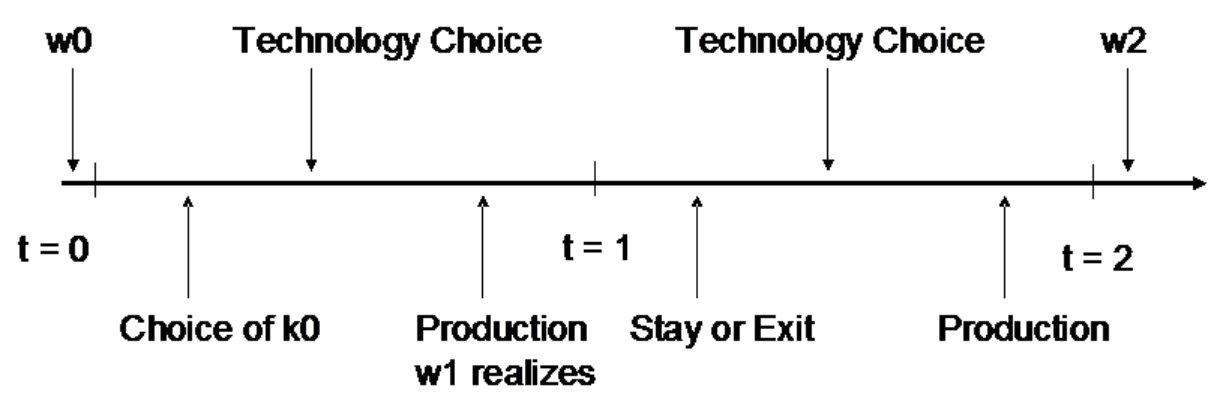

Figure 3: Timing of the Simple Model

makes the investment choice $k_{1}$ and project choice again based on period 1 wealth $w_{1}$. In the last period, she simply consumes her final wealth $w_{2}$. The objective of an agent with initial wealth $w_{0}$ is to maximize her discounted consumption, with discount factor $\beta$ :

$$
V_{0}\left(w_{0}\right)=\max _{0 \leq k_{0} \leq w_{0}}\left\{\left(w_{0}-k_{0}\right)+\beta \max \left\{V_{1}\left(A k_{0}^{\alpha}\right),(1-p) V_{1}(0)+p V_{1}\left(\bar{z} k_{0}^{\alpha}\right)\right\}\right\}
$$

where $V_{t}\left(w_{t}\right)$ is the time $t$ value for an agent with wealth $w_{t}$.

It is convenient to work backwards. At time $t=2$,

$$
V_{2}\left(w_{2}\right)=w_{2} \text {. }
$$

At time $t=1$, an agent with $k_{1}>0$ will be indifferent between operating a safe project and a risky one. Assume that all agents will perform safely in this case, which is consistent with their choice if they were risk averse. For simplicity, I do not allow borrowing in the short model, and the period 1 value for a staying firm will be:

$$
V_{1}^{1}\left(w_{1}\right)=\max _{0 \leq k_{1} \leq w_{1}}\left\{\left(w_{1}-k_{1}\right)+\beta A k_{1}^{\alpha}\right\} .
$$

Let $k^{*}$ be the optimal capital choice without borrowing constraint. The value of a firm with wealth level $w_{1}$ at the beginning of period 1 will be given by

$$
V_{1}\left(w_{1}\right)=\max \left\{V^{0}, V_{1}^{1}\left(w_{1}\right)\right\} .
$$

Let $w_{1}^{*}$ be such that $V^{0}=V_{1}^{1}\left(w_{1}^{*}\right)$. Note that there is a kink at $w_{1}^{*}$ and $V_{1}\left(w_{1}\right)$ is convex in a neighborhood of $w_{1}^{*}$. This gives a firm with relatively low wealth level an incentive to take a risky project before it enters period 1 . At $t=0$, a firm makes the investment decision and chooses a project:

$$
\begin{aligned}
V_{0}\left(w_{0}\right) & =\max _{0 \leq k_{0} \leq w_{0}}\left\{\left(w_{0}-k_{0}\right)+\beta \max \left\{V_{1}\left(A k_{0}^{\alpha}\right),(1-p) V_{1}(0)+p V_{1}\left(\bar{z} k_{0}^{\alpha}\right)\right\}\right\} \\
& =\max _{0 \leq k_{0} \leq w_{0}}\left\{\left(w_{0}-k_{0}\right)+\beta \max \left\{V^{0}, V_{1}^{1}\left(A k_{0}^{\alpha}\right), p V_{1}^{1}\left(\bar{z} k_{0}^{\alpha}\right)+(1-p) V^{0}\right\}\right\} .
\end{aligned}
$$


To explicitly characterize a firm's project choice, it is useful to introduce the following condition on parameters.

Condition 1. $0<V^{0}<\alpha^{\frac{2 \alpha^{2}}{1-\alpha^{2}}} \beta^{\frac{1+\alpha^{2}}{1-\alpha^{2}}} \bar{z}^{\frac{1}{1-\alpha}} p^{\frac{2 \alpha^{2}}{1-\alpha^{2}}}\left(p^{1+\alpha}-p^{2}\right) /(1-p)$.

The risky and safe continuation values intersect at most once in the region where they are both greater than $V^{0}$. This condition ensures the existence of the intersection and makes the analysis tractable as shown in Proposition 1. The intuition is that given $(\bar{z}, p)$, the option value $V^{0}$ of exiting cannot be too high; otherwise, exit becomes very appealing, and so does the risky project. If the condition is violated, then all staying firms strictly prefer the risky project. In particular, if $V^{0}$ is given, this happens when $A$ is low enough.

Proposition 1. At $t=0$, if Condition 1 holds, then the continuation value functions associated with risky and safe projects intersect only once, and $\exists k_{0}^{I}$ and $k_{0}^{I I}$ such that $0<k_{0}^{I}<k_{0}^{I I}<k^{*}$, and the decision rule of a firm's owner with initial wealth $w_{0}$ will be one of the following:

1. If $0<w_{0} \leq k_{0}^{I}$, she consumes all $w_{0}$ in period 0 and exits in period 1 for sure;

2. If $k_{0}^{I}<w_{0}<k_{0}^{I I}$, she invests all $w_{0}$ in a risky project in period 0 , then with probability $p$, $w_{1}=\bar{z} k_{0}^{\alpha}$, she in turn invests all $w_{1}$ in period 1 ; with probability $1-p, w_{1}=0$, she exits in period 1;

3. If $k_{0}^{I I} \leq w_{0} \leq k_{0}^{A}$, she invests all $w_{0}$ in a safe project in period 0 , then invests all $w_{1}=A k_{0}^{\alpha}$ in period 1;

4. If $k_{0}^{A}<w_{0} \leq k^{*}$, she invests all $w_{0}$ in a safe project in period 0 , then invests $k^{*}$ and consumes the rest in period 1 ;

5. If $w_{0}>k^{*}$, she invests $k^{*}$ and consumes the rest in both periods.

The interesting region, or the "risky region," is the interval $\left[k_{0}^{I}, k_{0}^{I I}\right]$. The exiting option forms a lower bound in value function that is higher than in the case without exiting. This new lower bound alters the shape of the continuation value function, in particular, the continuation value function has a local convexity if safe project is chosen. This non-concavity region is roughly the same as the interval $\left[k_{0}^{I}, k_{0}^{I I}\right]$, in which firms have a limited amount of capital stock. Firms that fall into this region have the incentive to smooth out such convexity by entering a lottery and randomizing over possible outcomes, which is exactly the role that risky project plays in this model. The fraction of risk-taking firms will then be determined given the initial distribution 


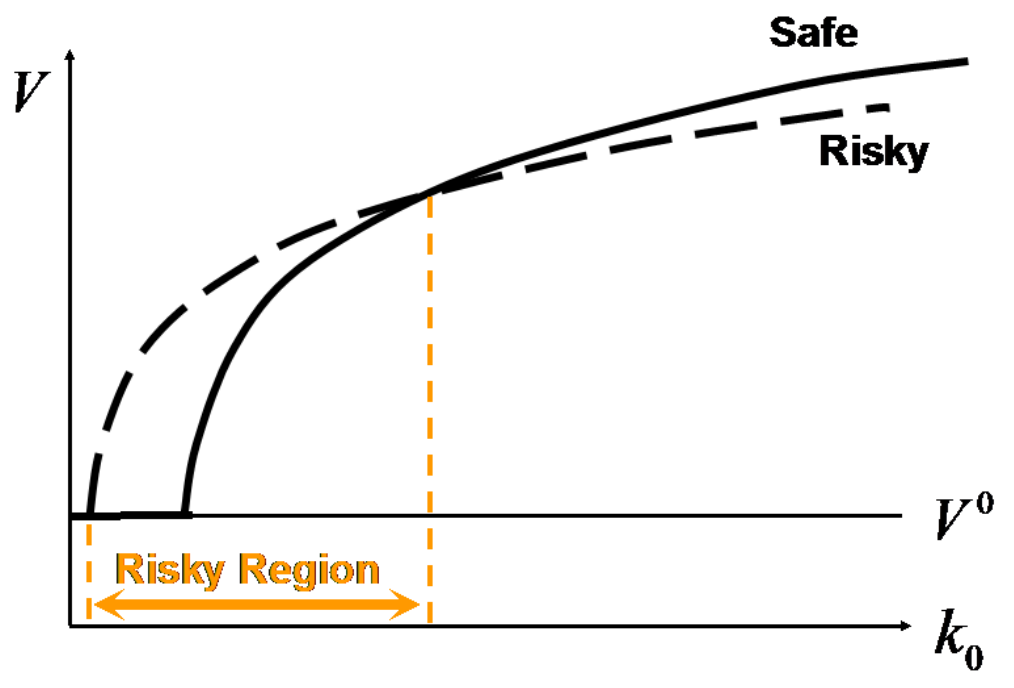

Figure 4: Continuation Values as Functions of Control Variable, $k_{0}$. The horizontal axis is $k_{0}$, and the vertical axis is the continuation value for each level of $k_{0}$. The solid curve is the safe continuation value $V_{1}\left(A k_{0}^{\alpha}\right)$, and the dashed curve is the risky continuation value $(1-p) V_{1}(0)+$ $p V_{1}\left(\bar{z} k_{0}^{\alpha}\right)$. The horizontal line is $V^{0}$. 
$G\left(w_{0}\right)$, and each of these firms bears the same risk in terms of the randomness of productivity ${ }^{10}$ As can be seen below, a change in $A$ drives the changes in the risky region and the fraction of risk-taking firms and leads to a different productivity dispersion.

Suppose that with probability $p$ the risky project is realized to have high productivity. The cross-sectional variance in realized productivity in period 0 , denoted as $\Gamma(p, \bar{z})$, is a function of $p$, the probability of good realization of the risky project, and $\bar{z}$, the good realization of productivity.

$$
\begin{aligned}
& \Gamma(p, \bar{z})=E_{w_{0}, Z}\left(Z^{2}\right)-\left[E_{w_{0}, Z}(Z)\right]^{2} \\
& =\sigma^{2}(p, \bar{z}) \Lambda(p, \bar{z})
\end{aligned}
$$

where $Z$ represents the productivity of the project a firm chooses, and $\Lambda(p, \bar{z}):=\frac{G\left(k_{0}^{I I}\right)-G\left(k_{0}^{I}\right)}{1-G\left(k_{0}^{I}\right)}$ in which $k_{0}^{I}$ and $k_{0}^{I I}$ are functions of $p$ and $\bar{z}$ as well. $\sigma^{2}(p, \bar{z})$ is simply the variance of the Bernoulli distributed productivity of the risky project, while $\Lambda(p, \bar{z})$ represents the measure of firms in the risky region. $\Gamma(p, \bar{z})$ is ex ante variance and coincides with realized dispersion in productivity, assuming a form of law of large numbers holds. At the same time, the aggregate or average output in period $0, O(p, \bar{z})$, is:

$$
\begin{aligned}
& O(p, \bar{z})=E_{w_{0}, Z}\left(F\left(Z, k_{0}\right)\right) \\
& =p \bar{z} \int_{k_{0}^{I}}^{k^{*}} w_{0}^{\alpha} d G\left(w_{0} \mid k_{0}>0\right)+p \bar{z}\left(k^{*}\right)^{\alpha} \frac{1-G\left(k^{*}\right)}{1-G\left(k_{0}^{I}\right)} .
\end{aligned}
$$

\subsection{Comparative Statics}

The nature of the simple model does not permit cyclical features. Therefore, I will instead analyze the comparative statics mimicking different times of business cycles. In particular, I use $A$, the average productivity, as the economic condition indicator, which corresponds to the average TFP in the data. In the model, a change in $A$ can result from either a change in $p$, or in $\bar{z}$, or in both. Provided that the bad outcome of the risky project is normalized to be zero, $\bar{z}$ then determines the range, the variance of the Bernoulli productivity $\sigma^{2}(p, \bar{z})$, and the measure of the risky region $\Lambda(p, \bar{z})$. At the same time, $\sigma^{2}(p, \bar{z})$ and $\Lambda(p, \bar{z})$ are also nontrivial functions of $p$. When $A, p$, and/or $\bar{z}$ changes, the resulting change in the riskiness of a risky project, that is, variance $\sigma^{2}(p, \bar{z})$ or range $\bar{z}$, is called the "riskiness effect," as such change directly affects the

\footnotetext{
${ }^{10}$ Once again, the same risk results from the assumption that only one way of randomization is permitted in the model for simplicity. To relax this restriction, one can assume that each firm can choose any distribution on productivity so long as the expectation remains $A$, which results in a risky region larger than $\left[k_{0}^{I}, k_{0}^{I I I}\right]$. However, while making the model much more complicated, this will not alter the result qualitatively, and neither will it provide more insight into the model.
} 
riskiness of available project; and the change in the measure of firms in the risky region, $\Lambda(p, \bar{z})$, is the "mean effect," as the change in mean $A$ determines the slope of continuation functions, which in turn affects the width of the risky region. The interesting one is the mean effect, which highlights the novel mechanism of the model; therefore, I consider a particular change in $A$, such that $\bar{z}$ is held unchanged and $p$ is controlled for in a certain way to fully eliminate the riskiness effect, and I examine the resulting mean effect.

Proposition 2. Let $V^{0}$ and $\bar{z}$ remain unchanged and assume Condition 1 always holds. Let $A \in\left\{A^{H}, A^{L}\right\}=\left\{p^{H} \bar{z}, p^{L} \bar{z}\right\}, p^{H}$ and $p^{L}$ be such that $p^{H}>p^{L}>0$. Suppose the distribution of initial wealth $G(\cdot)$ is Pareto or uniform and the lower bound of its support is below $k_{0}^{I}$ when the good outcome of the risky project is w.p. $p^{H}$. Then:

1. $O\left(p^{H}, \bar{z}\right)>O\left(p^{L}, \bar{z}\right)$;

2. $\Lambda\left(p^{H}, \bar{z}\right)<\Lambda\left(p^{L}, \bar{z}\right)$.

To control the riskiness effect, assume $p^{H}+p^{L}=1$, then:

3. $\sigma^{2}\left(p^{H}, \bar{z}\right)=\sigma^{2}\left(p^{L}, \bar{z}\right)=\bar{z}^{2} p^{H} p^{L}$;

4. $\Gamma\left(p^{H}, \bar{z}\right)<\Gamma\left(p^{L}, \bar{z}\right)$.

According to this proposition, given $\bar{z}$ fixed, $A$ (or $p$ ) summarizes the aggregate state; higher $A$ then means good times. When the aggregate state is good, the total output is high, and this is always the case whether the riskiness effect is controlled for or not. Meanwhile, the risky region is smaller in good times, which in turn leads to a smaller fraction of risk-taking firms, regardless of the riskiness effect. The assumption on Pareto or uniform distribution is not very restrictive. In fact, it can be any distribution that results in the same pattern of change in the fraction of risky firms. I choose Pareto distribution to mimic the actually observed size distribution of firms, which is only a sufficient but not necessary condition for the desired change in risky fraction. When the riskiness effect is controlled for, the riskiness of a risky project remains unchanged; therefore it is the change in the fraction of risk-taking firms that drives the change in resulting productivity dispersion, or the average riskiness that firms choose to take, measured as the variance in productivity.

If $\bar{z}$ is not fixed or $p$ is not controlled for in such a way, then it is impossible to disentangle the mean effect from the riskiness effect, and these two effects jointly determine the resulting change in the cross-sectional dispersion in productivity. In fact, in the calibrated quantitative model, it 


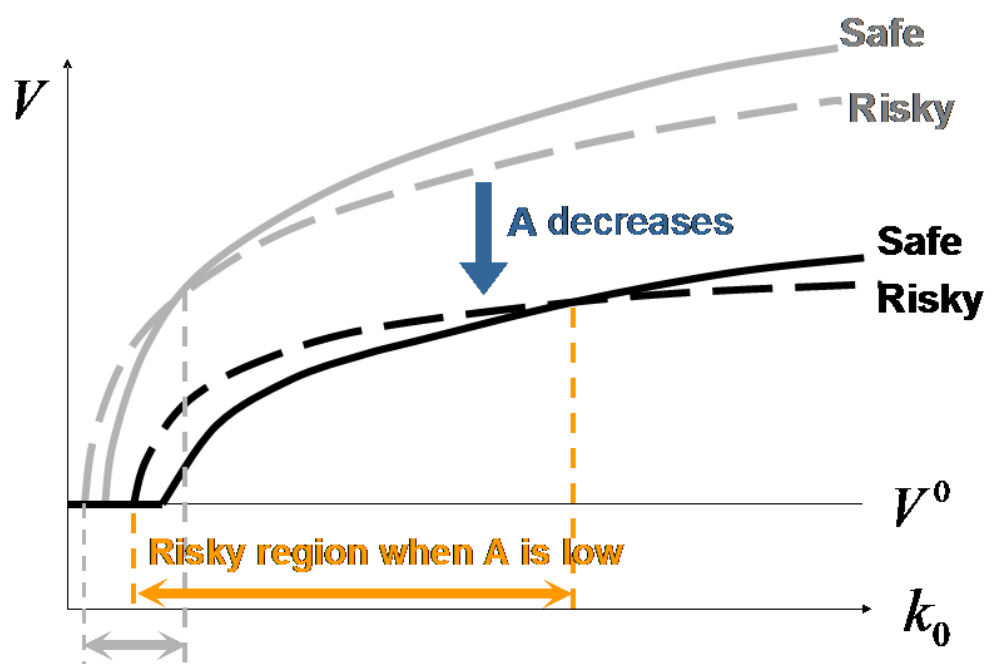

' Risky regiion when $\mathbb{A}$ is high

Figure 5: Comparative Statistics.

turns out that the riskiness effect is too small to a generate significant difference in simulated results.

Figure 5 illustrates what happens to the model if $A$ decreases, as described in Proposition 2. When $A$ is low, the exiting threshold increases and more firms exit. At the same time, low $A$ also leads to a larger risky region and a greater fraction of risk-taking firms; so now there are more firms that strictly prefer the risky project. As a result, if the change in $A$ is controlled for as specified before, the average risk that firms choose to take is also larger and so is the realized productivity dispersion. To summarize, the key step for the model to generate a countercyclical productivity dispersion is the change in the risky region as the aggregate state changes. And it is mainly an enlarged fraction of risk-taking firms that causes a larger productivity dispersion in bad times. This mechanism remains in the quantitative model with infinite horizon. In fact, if the aggregate state follows a Markov process with only two possible outcomes of $A^{H}$ and $A^{L}$ controlled for in a similar way, then without introducing other features, the negative correlation between the aggregate state and productivity dispersion is still almost perfect.

\section{Quantitative Model}

The simple three-period model illustrates the main mechanism in a tractable setting. However, it is only feasible to look at the comparative statics in an essentially static model with three stages. 
Therefore, a richer model with infinite horizon is built in this section to include more realistic business cycle features and to examine the quantitative performance of the mechanism.

\subsection{Setup}

Time is discrete, with infinite horizon. The firms that have survived at least one period are called incumbents. There is a constant mass $M>0$ of potential entrant firms every period, each of which draws its initial capital $k_{0}$ from a distribution $G^{0}\left(k_{0}\right) . G^{0}(\cdot)$ determines the number and size distribution of newly born firms. Once it has entered, an entrant acts as an incumbent thereafter as long as this firm stays. The production function is the same as in the simple model, $F(Z, k)=Z k^{\alpha}$, with $0<\alpha<1$ and $Z$ being the realized productivity depending on project choice. ${ }^{11}$ At the beginning of each period, all firms observe average productivity $A$. An incumbent firm owner makes the choice between staying and exiting; meanwhile, all firms also face an exogenous exiting probability $\eta>0$. I allow additional exogenous exiting to generate the death of large firms, which always choose the safe project, as in the simple model. If an incumbent exits, the owner closes her firm and sells all capital stock. Once exiting, the firm cannot re-open for business again in the future. A staying firm then decides the amount of the next period's working capital $k^{\prime}$ and whether to adopt the safe project or the risky one. Again, assume the full attention of a firm's owner and complete utilization of plant capacity as a prerequisite of production. After production, capital depreciates at rate $\delta$.

Under these settings, firms in this economy are heterogeneous in realized productivity, capital stock, and depreciation rate in each period; provided a realization of the aggregate state, project choice, investment, and depreciation jointly determine the incumbent's next period disposable

\footnotetext{
${ }^{11}$ In fact, $F(Z, k)=Z k^{\alpha}$ can be interpreted as a firm's profit function, that is, the revenue net of the cost for variable factors, for example, labor and materials. Specifically, assume that a plant faces an inverse demand function $P(y)=B y^{-b}$, and therefore its revenue becomes $R(y)=B y^{1-b}$. Suppose the actual production function is $y=\tilde{A} k^{\tilde{\alpha}} l^{\tilde{\phi}}$, and the price for other factors is $\omega$. Then after optimization of $l$, the revenue function becomes

$$
R=\left(B \tilde{A}^{1-b}\right)^{1 /(\tilde{\phi}(1-b))}[\tilde{\phi}(1-b) / \omega]^{\tilde{\phi}(1-b) /(\tilde{\phi}(1-b)-1)} k^{\tilde{\alpha}(1-b) /(\tilde{\phi}(1-b)-1)},
$$

and profit function

$$
\pi=(1-\tilde{\phi}(1-b)) R .
$$

Redefining variables gives the form of $Z k^{\alpha}$. Therefore, $Z$ in the model is more appropriately interpreted as measured revenue total factor productivity that includes information from the demand side, instead of the actual production technology. For the same reason, parameter $A$, shown later in the model, will also be interpreted as the aggregate state of the model economy, and a change in $A$ is more than just a "technology shock." Under this specification, it is easier to link the model to the data because only TFPR (TFP calculated using revenue data) is required for this model, but not TFPQ (actual TFP). Admittedly, TFPR is much easier to compute.
} 
resource.

The aggregate state for the model economy $A$ evolves as a Markov chain with $A \in \mathbb{A}=\left\{A_{1}, \ldots, A_{N_{A}}\right\}$, and transition probability $\pi_{i j}=\operatorname{Pr}\left(A^{j} \mid A^{i}\right)$. In particular, this Markov chain is a discretized $\operatorname{AR}(1)$ process, such that $\ln A_{t}=\rho_{A} \ln A_{t-1}+\sigma_{u} u_{t}$, where $\rho_{A} \in(0,1)$ is the serial correlation, and $u_{t} \sim N(0,1)$ is white noise. Following conventional real business cycles models, I assume time-invariant volatility in $A$, in terms of constant $\sigma_{u}$. This implies that the driving force of this modelled economy is the traditional "technology shocks," that is, the change in the "first moment". This is different from Bloom (2009) and Bloom et al. (2010), who use time-varying higher moments as the pure source of aggregate fluctuation. Meanwhile, this is also distinct from, for example, Bachmann and Bayer (2011) and Chugh (2010), who allow time-varying higher moments in addition to the usual first moment movement to account for the countercyclical dispersion observed in the data. I do not allow $\sigma_{u}$ to change over time based on the following considerations: (1) $\sigma_{u}$ is time series volatility, which is not the same as the observed cross-sectional dispersion, (2) this model emphasizes a mechanism through which time-varying $A$ generates realized productivity dispersion, and there is no need to introduce additional variation, and (3) fixed $\sigma_{u}$ implies fixed unconditional mean of $A$.

Production is costly. In each period, a staying and active firm needs to pay a fixed operating cost, and if the firm needs to increase or decrease its capital stock, it pays a capital adjustment cost as well. Mainly following Cooper and Haltiwanger (2006) and Bloom (2009), I assume the capital adjustment cost consists of two parts: (1) a non-convex cost, and (2) a transaction cost. The non-convex cost represents the opportunity cost when a firm is under capital adjustment. Specifically, this firm forgoes a fraction $c_{k}$ of its production if there is capital adjustment in a given period. The transaction cost represents the partial irreversibility. When a firm needs to increase capital, the price paid for every unit of new capital is normalized to be one, where the price is interpreted as how many units of output are needed to get one unit of capital. However, if a firm wants to reduce capital, the selling price for each unit of capital is $\theta<1$.

Each time period has several stages, which resembles period 1 in the simple three-period model.

- Stage 1: Observation of state variables. Aggregate state $A$ is realized. An incumbent firm observes $A$ and enters this period with remaining capital after depreciation, $(1-\delta) k$, and together with last period's production $F\left(Z_{-1}, k\right)$, where $Z_{-1}$ is the realization of last period's productivity of this firm. A potential entrant draws $k_{0}$ and observes $A$.

- Stage 2: Entry and exit. An entrant with $\left(k_{0}, A\right)$ enters if there is positive expected profit. An incumbent exits either voluntarily based on continuation values or exogenously with probability $\eta$. 


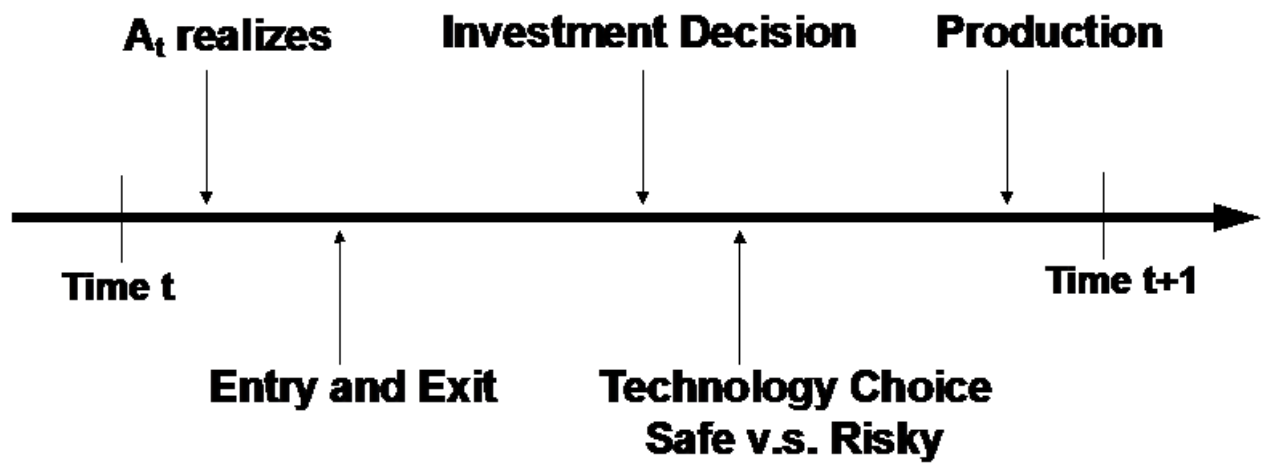

Figure 6: Timing of the Quantitative Model

- Stage 3: Investment and project decision. Both staying incumbents and newborn firms decide how much to invest and then choose between safe and risky projects. At the same time, the operating cost and capital adjustment cost are paid.

- Stage 4: Production. Production takes place in the form $F\left(Z, k^{\prime}\right)$, where $k^{\prime}$ is the new working capital, and $Z$ is productivity. If a firm chooses the safe project, then productivity is deterministic, $Z=A$. Otherwise, with probability $p(A)$, the risky project turns out to be a success, $Z=\bar{z}$, and with probability $1-p(A)$, it fails, and $Z=0$.

\subsection{Individual Decision}

An Incumbent's Problem. At the beginning of each period, an incumbent firm is characterized by $\left(Z_{-1}, k, A\right)$, where $Z_{-1} \in\left\{A_{-1}, 0, \bar{z}\right\}$ is the realized productivity in the last period for a specific firm, which can be the safe productivity $A_{-1}$, the bad realization 0 , or the good realization $\bar{z} ; k$ is the total amount of capital that was used in the previous period, and $A$ represents the economic conditions of the current period. ${ }^{12}$

The first choice an incumbent firm owner makes is between continuing to operate and closing the firm and leaving.

$$
V\left(Z_{-1}, k, A\right)=\max (1-\chi) V^{1}\left(Z_{-1}, k, A\right)+\chi V^{0}\left(Z_{-1}, k, A\right),
$$

where $\chi \in\{\eta, 1\}$ is the exiting choice, and $\eta$ is the exogenous exiting hazard. If a firm with $\left(Z_{-1}, k, A\right)$ chooses to exit, the value is:

$$
V^{0}\left(Z_{-1}, k, A\right)=\theta(A)\left(Z_{-1} k^{\alpha}+(1-\delta) k\right) ;
$$

\footnotetext{
${ }^{12}$ The distribution of firms is not a state variable in this model, because it has an essentially partial equilibrium setup, and agents do not need to forecast future prices using information on distribution.
} 
where $\theta(A)<1$ is the fraction of resources a firm owner can take away when exiting, which is actually a resale price and is potentially a function of $A$. If this firm chooses to stay, the owner must then decide on investment, $i$, and a project choice, safe or risky. The capital stock evolves as follows

$$
k^{\prime}=(1-\delta) k+i
$$

such that $k^{\prime} \geq k_{\min }>0$, where $k_{\min }$ is a very small positive number providing a lower bound of capital stock. The operating $\operatorname{cost} C\left(i ; Z_{-1}, k, A\right)$ of a firm consists of a fixed cost $c_{f}$ and a capital adjustment cost:

$$
C\left(i ; Z_{-1}, k, A\right)=c_{f}+c_{k} F\left(Z_{-1}, k\right) 1_{\{i \neq 0\}}+(1-\theta(A))(-i) 1_{\{i<0\}} .
$$

Apart from the fixed operating cost, there are two forms of capital adjustment costs: a non-convex adjustment cost and partial irreversibility. Actively adjusting capital stock and choosing $i \neq 0$ costs a firm $c_{k}$ fraction of its revenue from the last period's production. In addition, if a firm reduces its scale, it can only sell its current capital possession at price $\theta(A)<1$. The fixed operating cost is to generate endogenous exiting behavior, and therefore, it creates a non-concave portion in the lower end of a firm's value function. The adjustment cost plays a double role: one is to capture the observed inaction in investment and slow down the change in firm size, and the other is to dampen firms' reaction to changes in aggregate states so that the correlation between productivity dispersion and the aggregate state is not too close to -1 . Combining these pieces gives the flow profit of this firm $D\left(k^{\prime} ; Z_{-1}, k, A\right)$, and

$$
P\left(i ; Z_{-1}, k, A\right)=F\left(Z_{-1}, k\right)-i-C\left(i ; Z_{-1}, k, A\right) \geq 0 .
$$

I enforce non-negative profit as a constraint. The firm also has to choose between a safe and a risky project. A safe project produces $F\left(A, k^{\prime}\right)$ for sure; a risky project results in productivity at $\bar{z}$ with probability $p(A)$ and 0 with $1-p(A)$. If the safe one is chosen, the firm gets:

$$
V_{\text {safe }}^{1}(i ; k, A)=\mathbb{E}_{A^{\prime}, \delta^{\prime}}\left[V\left(A, k^{\prime}, A^{\prime}\right) \mid A\right]
$$

and likewise,

$$
V_{\text {risky }}^{1}(i ; k, A)=p(A) \mathbb{E}_{A^{\prime}}\left[V\left(\bar{z}, k^{\prime}, A^{\prime}\right) \mid A\right]+(1-p(A)) \mathbb{E}_{A^{\prime}}\left[V\left(0, k^{\prime}, A^{\prime}\right) \mid A\right] .
$$

Therefore, conditional on staying, an incumbent firm solves the following maximization problem:

$$
V^{1}\left(Z_{-1}, k, A\right)=\max _{i}\left\{P\left(i ; Z_{-1}, k, A\right)+\beta \max \left\{V_{\text {safe }}^{1}\left(k^{\prime} ; Z_{-1}, k, A\right), V_{\text {risky }}^{1}\left(k^{\prime} ; Z_{-1}, k, A\right)\right\}\right\} .
$$

Denote the state variables of an incumbent as $\psi=\left(Z_{-1}, k, A\right) \in \Psi$, with $\Psi$ being the set of all possible states. The solution to an incumbent's question with state $\psi$ is a list of policy functions 
$\{\chi(\psi), \tau(\psi), \iota(\psi)\}$ such that $(1) \chi(\psi)$ is the exiting choice, $\chi: \Psi \rightarrow\{\eta, 1\}$; and conditional on surviving, (2) $\tau(\psi)$ is the project choice, $\tau:\{\psi \in \Psi: \chi(\psi)=\eta\} \rightarrow\{0,1\}$, where 0 represents the safe project and 1 the risky one, and $(3) \iota(\psi)$ is the investment level, $\iota:\{\psi \in \Psi: \chi(\psi)=\eta\} \rightarrow \mathbb{R}$.

A Potential Entrant's Problem. A potential entrant draws initial capital holding $k_{0}$ from a invariant Pareto distribution $G^{0}\left(k_{0}\right)$ with parameter $\xi$. The value of staying outside the market is

$$
V_{0}^{0}\left(k_{0}, A\right)=\theta(A) k_{0}
$$

To start up a business, one must pay a setup cost $c_{e}$ from initial capital, and thereafter acts as an incumbent with state $\left(Z_{-1}, k, A\right)$ being $\psi_{0}=\left(0,\left(k_{0}-c_{e}\right) /(1-\delta), A\right)$. Hence, the payoff of opening a firm will be:

$$
V_{0}^{1}\left(k_{0}, A\right)=V^{1}\left(0,\left(k_{0}-c_{e}\right) /(1-\delta), A\right) .
$$

A new firm will be born if

$$
V_{0}^{1}\left(k_{0}, A\right)>V_{0}^{0}\left(k_{0}, A\right) .
$$

The solution to this problem is a binomial entry choice $\varepsilon: \Psi_{0} \subset \Psi \rightarrow\{0,1\}$, where $\Psi_{0}$ contains all possible $\psi_{0}$, and $\varepsilon\left(\psi_{0}\right)=1$ if an entrant enters and 0 otherwise.

\subsection{Aggregate Dynamics}

Given the solutions to the individual problems described before, $\{\chi(\cdot), \tau(\cdot), \iota(\cdot) ; \varepsilon(\cdot)\}$, it is straightforward to write down the transition dynamics for the distribution over $\psi=\left(Z_{-1}, k, A\right)$.

For an arbitrary $\psi \in \Psi$, either $\psi \in \Psi_{0}$ or $\psi$ can only be the state of an incumbent. I denote $\phi(\psi)$ as the measure or density of point $\psi=\left(Z_{-1}, k, A\right)$ at Stage 1 of a typical period with aggregate state $A$, before entry and exit takes place. If $\chi(\psi)=1$, then a firm with this state exits for sure, and no other transition can happen. If $\chi(\psi)=\eta$, then with probability $\eta$ this firm exogenously exits, and with a complementary probability, it stays. Conditional on staying, if the firm chooses the safe project, $\tau(\psi)=0$, then its individual state becomes $(A,(k+\iota(\psi)))$. On the other hand, if the firm chooses the risky project, $\tau(\psi)=1$, then with probability $p(A)$ its individual state becomes $(\bar{z},(k+\iota(\psi)))$, and with probability $(1-p(A))$ it becomes $(0,(k+\iota(\psi)))$. Now turn to the newborns. Denote $g^{0}\left(\psi_{0}\right)$ as the entrant's measure or density at point $\psi_{0}$ determined by $G^{0}(\cdot)$. A newborn with $\psi_{0}$ enters if $\varepsilon\left(\psi_{0}\right)=1$. After entering, this firm acts exactly the same as a surviving incumbent with $\psi=\psi_{0}$. Finally, the aggregate state becomes $A^{\prime}$ with probability $\operatorname{Pr}\left(A^{\prime} \mid A\right), A^{\prime} \in \mathbb{A}$. Formally, suppose the aggregate state at Stage 1 of a period is $A^{\prime}=A_{j}$, and that of the last period is $A=A_{i}$, meaning that the realized productivity $Z$ is one of $\left\{A_{i}, \bar{z}, 0\right\}$. Every state not on the realization path has zero measure, or

$$
\phi^{\prime}\left(A, k^{\prime}, A^{\prime}\right)=0 \text { if } A \neq A_{i} \text { or } A^{\prime} \neq A_{j}
$$


where primed variables are ones realized in the same period as $A^{\prime}$. The rest of the states can then be divided into three groups by realization of $Z$, all of which come from both incumbents and newborns. For $Z=A_{i}$,

$$
\begin{aligned}
\phi^{\prime}\left(A_{i}, k^{\prime}, A_{j}\right)= & \int(1-\chi(\psi))(1-\tau(\psi)) \mathbf{1}_{\left\{\psi: k^{\prime}=(1-\delta) k+\iota(\psi)\right\}} \phi(d \psi) \\
& +M \int \varepsilon\left(\psi_{0}\right)\left(1-\tau\left(\psi_{0}\right)\right) \mathbf{1}_{\left\{\psi_{0}: k^{\prime}=(1-\delta) k_{0}+\iota\left(\psi_{0}\right)\right\}} g^{0}\left(d \psi_{0}\right),
\end{aligned}
$$

where variables with no prime are the ones observed one period back, with $\psi=\left(Z_{-1}, k, A_{i}\right)$ and $\psi_{0}=\left(0,\left(k_{0}-c_{e}\right) /(1-\delta), A_{i}\right)$. For $Z=\bar{z}$ or 0,

$$
\begin{aligned}
\phi^{\prime}\left(\{\bar{z}, 0\}, k^{\prime}, A_{j}\right)= & \int(1-\chi(\psi)) \tau(\psi) \mathbf{1}_{\left\{\psi: k^{\prime}=(1-\delta) k+\iota(\psi)\right\}} \phi(d \psi) \\
& +M \int \varepsilon\left(\psi_{0}\right) \tau\left(\psi_{0}\right) \mathbf{1}_{\left\{\psi_{0}: k^{\prime}=(1-\delta) k_{0}+\iota\left(\psi_{0}\right)\right\}} g^{0}\left(d \psi_{0}\right) .
\end{aligned}
$$

By independence, a fraction $p\left(A_{i}\right)$ has $Z=\bar{z}$, and the rest gets $Z=0$, that is,

$$
\begin{aligned}
\phi^{\prime}\left(\bar{z}, k^{\prime}, A_{j}\right) & =p\left(A_{i}\right) \phi^{\prime}\left(\{\bar{z}, 0\}, k^{\prime}, A_{j}\right) \\
\phi^{\prime}\left(0, k^{\prime}, A_{j}\right) & =\left(1-p\left(A_{i}\right)\right) \phi^{\prime}\left(\{\bar{z}, 0\}, k^{\prime}, A_{j}\right) .
\end{aligned}
$$

Given the distribution measure $\phi$ and $\phi^{\prime}$, the cross-sectional variance in productivity can be written as

$$
\begin{aligned}
\Gamma(A, \phi) & \propto \int \bar{z}^{2} \phi^{\prime}\left(\bar{z}, d k^{\prime}, d A^{\prime}\right)+\int A^{2} \phi^{\prime}\left(A, d k^{\prime}, d A^{\prime}\right)-\left[\int \bar{z} \phi^{\prime}\left(\bar{z}, d k^{\prime}, d A^{\prime}\right)+\int A \phi^{\prime}\left(A, d k^{\prime}, d A^{\prime}\right)\right]^{2} \\
& =\bar{z}^{2} p(A)(1-p(A)) \int \phi^{\prime}\left(\{\bar{z}, 0\}, d k^{\prime}, d A^{\prime}\right)=\sigma^{2}(A) \Lambda(A, \phi) .
\end{aligned}
$$

The expression of the cross-sectional variance can be simplified in this way due to the linearity of productivity in production function.

\subsection{Calibration}

Before I describe the calibration procedure, it is worth noting that the mass of potential entrants $M$ affects only the scale of the economy once other parameters are determined. Since the absolute scale is not of interest, the choice of $M$ is irrelevant. For a quantitative exercise, the number of potential entrants is fixed at 50,000 each period. Furthermore, without aggregate fluctuation, starting from zero incumbents, the economy always converges to a stationary state in the sense that the exit rate and the entry rate are equal and the scale is neither expanding 
nor shrinking, as long as there is positive measure of entrants at the beginning. And this is the case with or without agents expecting the aggregate state to be varying over time. The reason is simple. Since there is no aggregate fluctuation, the measure of entrants (inflow) is fixed each period. The measure of exiting firms (outflow) is a fraction of the remaining ones (stock). The outflow gradually increases to the same level as the inflow, and it is at this point that the scale of stock stops changing. Consequently, the entry and exit rates are the same. Because of this stationarity feature, the parameters that need to be internally determined are selected such that the statistics generated by the model at its stationary state match their empirical targets.

The setup of the model is very close to that of the standard model; therefore some of the parameter values are directly taken from the literature. One period is chosen to be one year. The discount factor is set as $\beta=0.938$ to match the long-run average for the U.S. firm-level discount rate, as in Bloom (2009). According to the same paper, capital depreciates at rate $\delta=0.1$. The production function, $F(Z, k)=Z k^{\alpha}$, is the same as the profit function in Cooper and Haltiwanger (2006), so I follow their estimation and set $\alpha$ to be 0.592. Taken from the same work, the standard deviation of the aggregate process $\sigma_{A}$ is 0.08 , and the serial autocorrelation $\rho_{A}$ is assumed to be 0.8 , which is within the range of the autocorrelation of a common shock 0.76 and that of an idiosyncratic shock 0.885 estimated in that paper.

The good productivity realization is predetermined as $\bar{z}=2$ so that the probability of getting $\bar{z}$ is always around a half. This is to minimize the riskiness effect by controlling for the uncertainty associated with the binary-outcome risky project. The exogenous exiting hazard $\eta$ that affects all firms alike is set to be $2 \%$, which is in line with the exiting rate of large plants found by, for example, Lee and Mukoyama (2008). On the entrant side, it has been mentioned that the choice of $M$ is not important. The distribution of the initial endowment $G^{0}$ is Pareto such that, with slight abuse of notation, $G^{0}\left(k_{0}\right)=1-\left(k_{\min } / k_{0}\right)^{\xi}$ with $\xi>0$. Clearly, $\xi$ governs the shape of the initial endowment distribution and it in turn determines the model-generated firm size distribution. Ideally, this generated distribution will also have a shape close to Pareto; however, the assumption of one common productivity shock and no idiosyncratic shocks makes this task infeasible. This can be corrected by introducing heterogeneous productivity, yet this practice will not provide more economic insight into this model. Therefore, for the numerical results, I set $\xi=1$.

The remaining parameters to be internally calibrated are capital resale price $\theta$, capital adjustment cost as a fraction of profit $c_{k}$, fixed operating cost $c_{f}$, and entry cost $c_{e}$. The model suggests that I shall look at the statistics of firm dynamics and the investment rate distribution, and the remaining parameters $\left(\theta, c_{k}, c_{f}, c_{e}\right)$ are selected via simulated method of moments. The targets regarding firm dynamics are taken from Lee and Mukoyama (2008), and those on investment rate 
distribution are from Cooper and Haltiwanger (2006). I also compute from the model the average five-year transition rates between different size classes, and I compare the generated numbers to the actual rates found by Acemoglu, Akcigit, Bloom, and Kerr (2011) using census data. The parameters are calibrated without aggregate fluctuation, and the aggregate state sequence, $\left\{A_{t}\right\}$, is set to be constant at its mean, but the firms still expect the future states to be changing according to the transition probability of $A, \pi_{i j}$.

Table 3. Parameter Values and Rationale ${ }^{13}$

\begin{tabular}{lll}
\hline Parameters & Description & Notes \\
\hline \hline $\begin{array}{l}\text { Aggregate Fluctuation } \\
\bar{z}=2\end{array}$ & Good productivity realization. & Predetermined. Normalization. \\
$\rho_{A}=0.8$ & Autocorrelation. & Cooper and Haltiwanger $(2006)$ \\
$\sigma_{u}=0.048$ & Var. of innovation s.t. $\sigma_{A}=0.08$. & Cooper and Haltiwanger $(2006)$ \\
Production & & \\
$\alpha=0.592$ & Production function parameter. & Cooper and Haltiwanger $(2006)$ \\
$\beta=0.938$ & Discount factor. & Bloom $(2009)$ \\
$\delta=0.1$ & Capital depreciation rate. & Bloom (2009) \\
$\eta=0.02$ & Exogenous exiting probability. & Lee and Mukoyama $(2008)$ \\
$\theta=0.84$ & Capital resale price. & Internally determined. \\
$c_{f}=1.62$ & Fixed operating cost. & Internally determined. \\
$c_{k}=0.165$ & Capital adjustment cost. & Internally determined. \\
Entrants & & \\
$c_{e}=0.1$ & Entry cost. & Internally determined. \\
$\xi=1$ & Shape of $G^{0}$. & Predetermined. \\
\hline
\end{tabular}

Calibrated parameter values are summarized in Table 3, and simulated moments are compared with their empirical counterparts in Table 4. Cooper and Haltiwanger (2006) compute a thorough set of investment moments using a balanced panel from the LRD from 1972 to 1988. The modelgenerated moments are close to their target with expected exceptions. The standard deviation in

13 I also tried several other sets of parameters. The negative sign of the correlations between aggregate state and dispersion measures is robust, which is not surprising because the mechanism works under mild restrictions of parameter space. However, it is true that the fraction of risky firms is sensitive to the shape of the value function. In particular, when $\beta$ is high, future profit flows are important, and the risky fraction declines and so does the exit rate. The realizations of $\delta$ are set to be $\{0.05,0.1,0.2,0.5,1\}$ with probabilities $\{0.69,0.155,0.1,0.05,0.005\}$, respectively. 
investment rates is much lower than in the data, because when the aggregate fluctuations are shut down, there is no idiosyncratic uncertainty other than the amount of risk a firm chooses to take. With a constant aggregate state and no growth, the model-generated mean level of the investment rate, together with the fraction of large and positive investment rates, is below the target as well. The other set of targets concerns the entry and exit dynamics of firms, which are taken from Lee and Mukoyama (2008). They use the ASM portion of the LRD from 1972 to 1997 to analyze the behavior of plants. At the same time, I look at the five-year transition rates between different size classes obtained by Acemoglu et al. (2011) using the CM portion. Firms are divided into two size classes, small and large, by median shipments, and the third class is "not-in-business." For example, the transition rate from the small class to the large class is computed as the fraction of originally small firms that became large ones in the next census. Since the census data are only available every five years, I let the model produce the same transition rates for every five periods. Due to different sources of data, I choose to hit a number within the range of empirically computed entry and exit rates. The model failed to reproduce the eight transition rates, although it managed to capture the fact that small firms have higher exiting rates than large ones. Without assuming idiosyncratic shocks, the model cannot generate a highly right-skewed size distribution with a relatively small median; therefore, the simulated exit rate is lower. At the same time, no further heterogeneity causes the large transition rates between large and small classes. 
Table 4. Moments Generated from Model and Targets

\begin{tabular}{lcc}
\hline & Model & Data \\
\hline \hline Investment & & \\
Mean of investment rate & 0.097 & 0.122 \\
Std. Dev. of investment rate & 0.157 & 0.337 \\
Fraction of inaction & 0.059 & 0.081 \\
Fraction w. positive investment & 0.889 & 0.815 \\
Fraction w. positive investment burst & 0.064 & 0.186 \\
Fraction w. negative investment burst & 0.033 & 0.018 \\
\multicolumn{1}{c}{ Data Source: Cooper and Haltiwanger $(2006)$} \\
\hline Entry and Exit & 0.070 & 0.062 \\
Mean entry rate & 0.070 & 0.055 \\
Mean exit rate & 0.75 & 0.60 \\
Relative size, entering & 0.58 & 0.49 \\
Relative size, exiting & \multicolumn{2}{c}{ Data Source: Lee and Mukoyama } \\
\multicolumn{2}{c}{$(2008)^{14}$} \\
\hline
\end{tabular}

\subsection{Quantitative Results}

The mechanism explained in the illustrative three-period model remains at work in the quantitative model with infinite horizon. The option to exit forms a lower bound for an incumbent's continuation value function, and in a conventional model without the additional choice of risky project, this lower bound in turn creates a non-concave portion on the continuation value at the lower end with low capital levels. When the choice of risky project is allowed as in this model, firms with capital levels in this portion have an incentive to smooth out the non-concavity by taking the risk. Of course, anticipating the future option of the risky project, the continuation value function associated with the safe one becomes less convex compared to the conventional case.

The business cycle features can now be introduced in a more realistic fashion than comparative statics. Without recalibrating, I add the aggregate fluctuation by simulating a sequence of realizations of productivity level $A$, and let the model evolve accordingly. As the aggregate state changes, the reaction of firms is still very similar to the comparative statics in the simple model.

\footnotetext{
${ }^{14}$ Lee and Mukoyama (2008) calculate the relative sizes of entering and exiting firms based on the number of employees.
} 
If $A$ drops, the slopes of both risky and safe continuation value functions decrease, which forms a larger portion where the risky project is strictly better. Consequently, a larger fraction of firms opt to take the risk, which results in a larger cross-sectional standard deviation in productivity. The opposite happens when $A$ increases. Nonetheless, given the frictions and the law of motion of the aggregate state, the magnitude of the changes in the fraction of risk taking firms and in the resulting standard deviation in productivity is history dependent.

The main goal of this numerical exercise is to show that changes in the level of $A_{t}$ alone can generate countercyclical firm-level productivity dispersion as a result of a firm's risk-taking behavior, without introducing any time-varying volatility in the driving force, $A_{t}$. The fluctuation in productivity $A$ follows the Markov process specified in Table 3, and not surprisingly, it is positively correlated with total output with correlation coefficient 0.4030 ( $\mathrm{p}$-value $=0.0000$ ). Therefore, the cross-sectionally averaged productivity can serve as an alternative cyclical indicator. The measures for productivity dispersion are chosen to be (1) the standard deviation of cross-sectional distribution of realized $Z$, productivity, (2) the fraction of firms that prefer the risky project, and (3) the $95 \%$ to $5 \%$ interpercentile range of realized $Z$, which is the value of $Z$ at the 95 th percentile minus the value of $Z$ at the 5 th percentile.

Table 5. Generated Cyclicality

\begin{tabular}{lccc}
\hline \multicolumn{3}{c}{ Cyclicality: Correlations (p-value) with Cyclical Indicators } \\
\hline \hline \multicolumn{2}{c}{ Variables of Interests } & \multicolumn{2}{c}{ Cyclical Indicators } \\
\cline { 3 - 4 } & \multicolumn{2}{c}{ Avg. Productivity, A } & Total Output, $O$ \\
\hline Productivity Dispersion & $\Lambda$ & $-0.4450(0.0000)$ & $-0.6969(0.0000)$ \\
Frac. of Risky Firms & $I P R_{5}^{95}$ & $-0.4544(0.0000)$ & $-0.6063(0.0000)$ \\
Interpercentile Range 95\%-5\% & $r^{E N}$ & $0.0314(0.4830)$ & $-0.7679(0.0000)$ \\
Entry Rate & $r^{E X}$ & $-0.4774(0.0000)$ & $-0.5649(0.0000)$ \\
Exit Rate & & & \\
\hline
\end{tabular}

Table 5 shows that the correlation coefficients between productivity dispersion and cyclical indicators are significantly negative, and the absolute values are in line with the data counterparts. In fact, the correlation between productivity dispersion and total output is even larger in scale. Moreover, the cyclicality of productivity dispersion measured is on a scale comparable to that of the fraction of firms that choose the risky project, and the movements show patterns very similar to those seen in Figure 8. This illustrates the mechanism that it is the change in the fraction of risk-taking firms that drives the cyclical movement of productivity dispersion. In bad times, more 


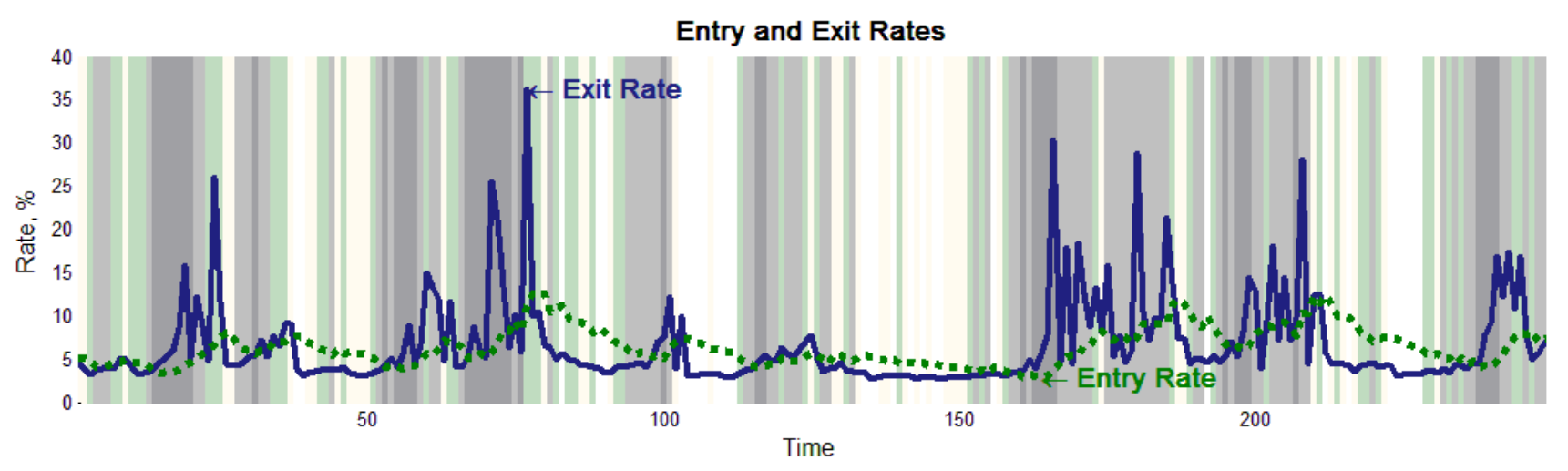

Figure 7: Simulated Sequences of Entry and Exit Rates. The solid line represents exit rates, and the dashed line records entry rates. Grey bars indicate the value of $A$ as in the previous figure.

firms are willing to take the risk and randomize their future values. Consequently, the resulting dispersion, measured as the standard deviation of cross-sectional productivity distribution, is larger and so is the interpercentile range. ${ }^{15}$ The assumed binomial outcome of a risky project has the potential to impact the behavior of the dispersion; however, such impact is controlled for at a much smaller scale by the choice of $\mu_{A}$ and $\bar{z}$ and does not alter the main pattern. A somewhat unusual result is the significantly negative correlation between total output and entry rates. This is a result of modelling technique. The entry decision of potential entrants depends largely on the discounted and expected future payoff, so the impact of the current aggregate state is minimal. At the same time, entry rates increase when the number of existing firms is smaller. However, the total output is not only a function of the current state $A$, but it also positively depends on the number of existing firms. These two forces drive the entry rate series to move in the opposite direction to total output.

Figure 7 plots the truncated series of entry and exit rates from the model simulation. The sequence of exit rates remains mostly in a reasonable scale between $3 \%$ and $12 \%$. On the contrary, there are quite a few episodes in which exit rates are really high. Extraordinarily high exit rates happen after a succession of bad realizations of the aggregate state $A$, when the number of

\footnotetext{
${ }^{15}$ Due to the model assumption, cross-sectional IPR in productivity can only be either $\bar{z}, \bar{z}-A_{t}$, or $A_{t}$, and does not have very interesting dynamics, although it is still countercyclical. This can be overcome by allowing a richer set of productivity lotteries and keeping the expected productivity to be $A$. For example, in addition to $(p(A), \bar{z})$, firms can also choose any $\left(p, \bar{z}_{A}\right)$ pair with binary outcomes such that $p \bar{z}_{A}=A$. Intuitively, the IPR measure in this case will again be negatively correlated with $A_{t}$ because smaller firms have the incentive to take even more risk in bad times than in the original case. Therefore, the range of realized productivities is wider, and potentially the IPR is larger and has more possible values.
} 


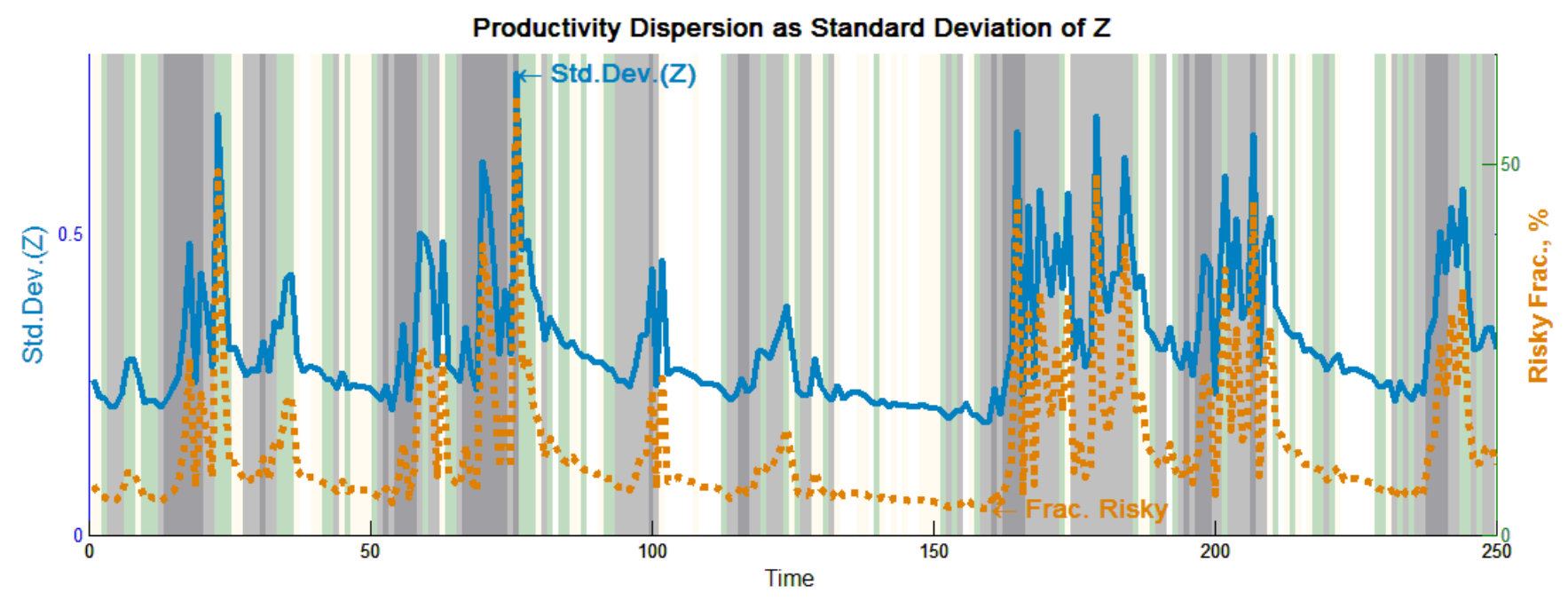

Figure 8: Simulated Sequences. The figure shows simulated sequences of (1) cross-sectional productivity dispersion measured as the standard deviation of realized productivity $Z$ (solid line, left axis), and (2) the fraction of firms that choose the risky technology (dotted line, right axis, in $\%$ ). The grey bars indicate the economic conditions as a value of $A$. In particular, darker bars represent lower values of $A$.

remaining firms is small. This is not surprising under the model assumptions that (1) all firms share the same serially correlated $A$ with no idiosyncratic shocks, and (2) given each realization of $A$, there is only one alternative risky project allowed. Figure 8 shows the truncated sequences of the countercyclical cross-sectional standard deviation in productivity and the fraction of risktaking firms in each period. The realized standard deviation in productivity mostly ranges from 0.25 to 0.65 , and the fraction of firms choosing the risky project is mostly between $10 \%$ and $55 \%$. The peaks of productivity dispersion and the risky fraction are associated with excessive exit rates, as the mechanism suggests.

Figure 9 shows how the productivity dispersion and fraction of risk-taking firms will react to a drop in $A$ from its mean level. Originally, the model is simulated in the same way as it is for calibration: the aggregate fluctuation is shut down by fixing $A$ at its mean level $\mu_{A}$, while the firms behave under the belief that $A$ evolves according to $\pi_{i j}$. Then, the value of $A$ suddenly and permanently switches to one standard deviation lower, $\mu_{A}-\sigma_{A}$, and the firms' belief remains unchanged. The risky fraction and productivity dispersion increase immediately upon impulse, then oscillate with an ascending trend, and eventually settle at a higher level. The two paths may seem unusual at first glance, but it is the joint work of (1) project choice and (2) capital adjustment costs. Upon the bad shock, as the result of a higher entering threshold, the number 

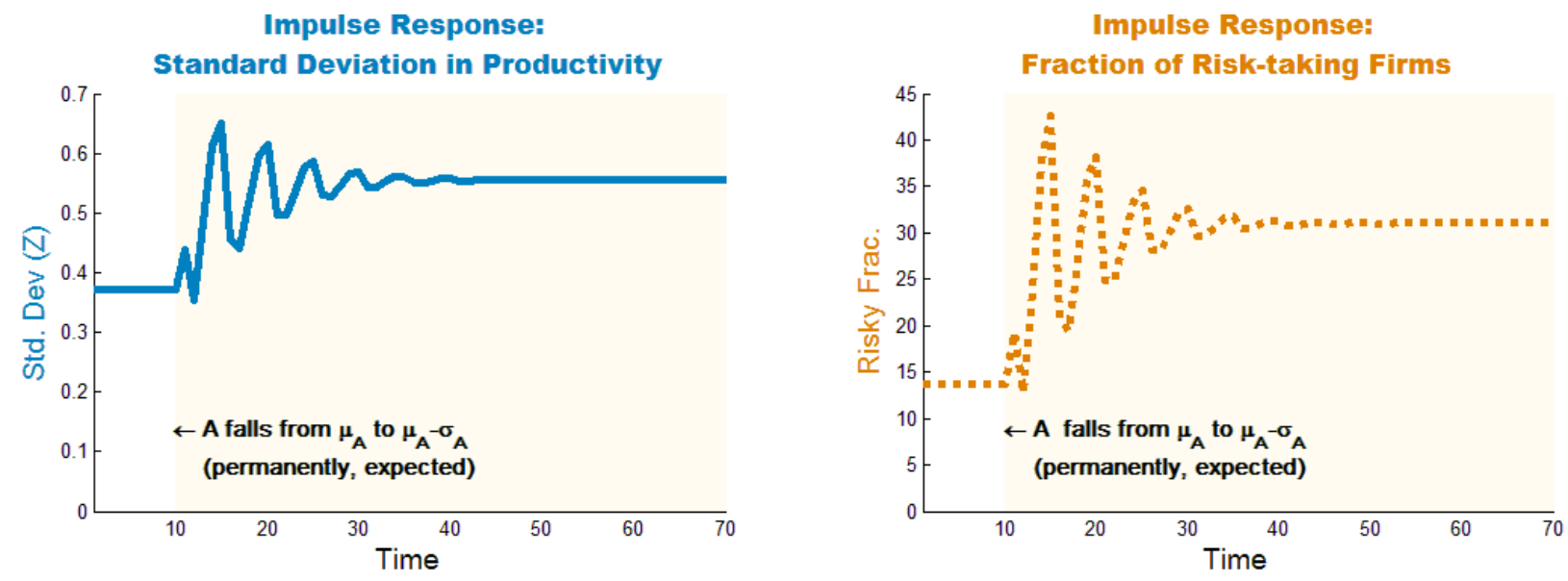

Figure 9: Impulse Responses. The figure shows impluse responses to a permanent (and expected) one-standard-deviation drop in the aggregate state. The left panel is the response of cross-sectional productivity dispersion, measured as the standard deviation in realized productivity. The right panel plots the response of the fraction of firms choosing the risky technology.

of entrants immediately drops to a lower level and then remains constant, and the scale of the economy, measured as the total number of remaining firms, decreases gradually to a new stable level. If capital adjustment costs are shut down, then both the absolute number and the fraction of risk-taking firms jump up upon impulse and drop in the following period. The reason for this sudden jump and drop is that the risky project becomes more appealing to firms with a wider range of capital stock when the shock hits, even though there is a higher probability of bad outcome. Consequently, a large number of firms exit due to their choice of the risky project, which leaves fewer firms remaining in the risky region and this causes the following drop. The absolute number of risky firms then gradually decreases while the fraction increases to a higher level because of the decreasing scale. This up-and-down trend is in line with what is shown in Figure 9, which is driven by the project choice. On the other hand, the oscillation is due to the capital adjustment costs, which create firms' inaction in investment and prevent firms from freely changing their capital stocks. Therefore, firms that should be in the risky region in the free adjustment case may now be outside, and vice versa. Note that the fraction of risky firms is around $14 \%$ when $A$ is kept at its mean, corresponding to the standard deviation in productivity at about 0.37 . Cooper and Haltiwanger (2006) find that the plant-specific idiosyncratic shock has a standard deviation of 0.64. Without assuming idiosyncratic risk, the calibrated stationary version of this model is capable of reproducing at least half of the micro-level standard deviation. 


\subsection{Discussions}

The comparison between the model-generated moments and their empirical counterparts suggests that this is not the whole story and that there are some possible extensions for future work. The additional moments in Table 6 indicate that the shape of the firm size distribution generated from the model is considerably different from the true one. Without altering the mechanism, introducing further heterogeneity in productivity can at least partly overcome this issue. In addition to that, adding more shocks, such as micro-level idiosyncratic shocks, and allowing for a richer set of risky projects can improve the fit of calibration targets, especially the standard deviation in investment rates. This can also help reduce the extraordinarily high exit rate under aggregate fluctuation. Again, these extensions will not alter the mechanism at work.

\begin{tabular}{lcc}
\hline \multicolumn{3}{c}{ Table 6. Additional Moments: Transition Rates } \\
\hline 5-Year Transition Rates & Model & Data \\
\hline \hline Small $\rightarrow$ Exit & 0.3491 & 0.5032 \\
Small $\rightarrow$ Small & 0.2900 & 0.4203 \\
Small $\rightarrow$ Large & 0.3609 & 0.0764 \\
Large $\rightarrow$ Exit & 0.2755 & 0.1803 \\
Large $\rightarrow$ Small & 0.3228 & 0.0564 \\
Large $\rightarrow$ Large & 0.4017 & 0.7633 \\
Entry $\rightarrow$ Small & 0.5070 & 0.7483 \\
Entry $\rightarrow$ Large & 0.4930 & 0.2517 \\
\multicolumn{2}{c}{ Data Source: } & Acemoglu et \\
\hline
\end{tabular}

A potentially more interesting extension is to generalize the model in a general equilibrium framework. One way to do so is to endogenize the capital market in which exiting firms and shrinking firm can sell their capital holdings to growing ones. In this way, there is an endogenous series of capital prices $\theta_{t}$, instead of a fixed capital resale price $\theta$. Naturally, $\theta_{t}$ is lower in bad times as more firms reduce their capital stocks, and it is higher in good times as more firms expand. But assuming that firms can employ a one-to-one capital production technique, $\theta_{t}$ will not exceed 1. As a robustness check, I let $\theta_{t}$ be a linear and increasing function of the aggregate state $A_{t}$ such that $\theta_{t}=\theta+b_{\theta}\left(A_{t}-\mu_{A}\right)$ with $b_{\theta}=0.5^{16}$. The results are presented in Table 7 . The similarity to the main result is not surprising, because the mechanism remains unchanged.

\footnotetext{
${ }^{16} \mathrm{I}$ also tried $b_{\theta}=1,1.5,2$ with $\theta_{t}$ constrained to be no higher than 1 . The results are very similar.
} 
Table 7. Robustness Check: Time Varying $\theta_{t}$

\begin{tabular}{lccc}
\hline \multicolumn{3}{c}{ Cyclicality: Correlations (p-value) with Cyclical Indicators } \\
\hline \hline \multirow{2}{c}{ Variables of Interests } & \multicolumn{2}{c}{ Cyclical Indicators } \\
\cline { 3 - 4 } & std.dev. $(Z)$ & $-0.4154(0.0000)$ & $-0.7622(0.0000)$ \\
\hline Productivity Dispersion & $\Lambda$ & $-0.4296(0.0000)$ & $-0.6992(0.0000)$ \\
Frac. of Risky Firms & $I P R_{5}^{95}$ & $-0.2483(0.0000)$ & $-0.7424(0.0000)$ \\
Interpercentile Range $95 \%-5 \%$ & $r^{E N}$ & $-0.0581(0.1943)$ & $-0.8128(0.0000)$ \\
Entry Rate & $r^{E X}$ & $-0.4679(0.0000)$ & $-0.6606(0.0000)$ \\
Exit Rate & & & \\
\hline
\end{tabular}

\section{Conclusion}

Productivity dispersion tends to be larger during recessions. The prevailing view is that increased uncertainty causes a decline in aggregate economic activities. However, although uncertainty matters, this story seems to contradict the observation that recessions lead an increase in productivity dispersion. To complement existing theories, I explore a simple mechanism through which aggregate fluctuations due to standard "technology shocks" can endogenously generate countercyclical dispersion in plant/firm-level productivity. I alter the standard industry dynamics model with business cycle features by incorporating project choice as part of the individual decision problem. By this feature, a firm in this model can then decide the riskiness of its production. The resulting productivity distribution is non-degenerate even if no other heterogeneity is modeled. The model provides the following predictions: small firms are more likely to take risks and have lower survival rates, but conditional on surviving, they exhibit higher productivity; a larger fraction of firms become risky in bad times, which also leads to higher exit rates; and realized micro-level productivity dispersion is larger in recessions.

\section{References}

[1] Acemoglu, D., U. Akcigit, N. Bloom, and W. Kerr (2011): "Innovation, Reallocation and Growth," Working Paper, University of Pennsylvania.

[2] Arellano, C., Y. Bai, and P. Kehoe (2009): "Financial Markets and Fluctuations in Uncertainty," Working Paper, Federal Reserve Bank of Minneapolis. 
[3] Bachmann, R., and C. Bayer (2011): "Uncertain Business Cycles - Really?" NBER Working Paper.

[4] Bachmann, R., and S. Elstner and E. Sims (2011): "Uncertainty and Economic Activity: Evidence from Business Survey Data," Working Paper, University of Michigan.

[5] Bachmann, R., R. Caballero, and E. Engel (2011): "Aggregate Implications of Lumpy Investment: New Evidence and a DSGE Model," Working Paper, University of Michigan.

[6] Bachmann, R., and G. Moscarini (2011): "Business Cycles and Endogenous Uncertainty," Working Paper, University of Michigan.

[7] Balasubramanian, N., and J. Sivadasan (2009): "Capital Resalability, Productivity Dispersion, and Market Structure," Review of Economics and Statistics, Vol. 91, 547-557.

[8] Berger, D., and J. Vavra (2011): "Dynamics of the U.S. Price Distribution," Working Paper, Yale University.

[9] Bloom, N. (2009): "The Impact of Uncertainty Shocks," Econometrica, Vol. 77, 623-685.

[10] Bloom, N., M. Floetotto, and N. Jaimovich (2010): "Really Uncertain Business Cycles," Working Paper, Stanford University.

[11] Campbell, J. R., (1998): "Entry, Exit, Embodied Technology, and Business Cycles," Review of Economic Dynamics, Vol. 1, 371-408.

[12] Chugh, S. (2010): "Firm Risk and Leverage-Based Business Cycles," Working Paper, Univeristy of Maryland.

[13] Clementi, G.L., and D. Palazzo (2010): "Entry, Exit, Firm Dynamics, and Aggregate Fluctuations," Working Paper, New York University.

[14] Cooper, R., and J. Haltiwanger (2006): "On the Nature of Capital Adjustment Costs," Review of Economic Studies, Vol. 73, 611-633.

[15] Dhawan, R. (2001): "Firm Size and Productivity Differential: Theory and Evidence from a Panel of US Firms," Journal of Economic Behavior \&3 Organization, Vol. 44, 269-293.

[16] Dunne, T., M. Roberts, and L. Samuelson (1988): "Patterns of Firm Entry and Exit in U.S. Manufacturing Industries," RAND Journal of Economics, Vol. 19, 495-515. 
[17] Eisfeldt, A.L., and A.A. Rampini (2006): "Capital Reallocation and Liquidity," Journal of Monetary Economics, Vol. 53, 369-399.

[18] Gertler, M., and S. Gilchrist (1994): "Monetary Policy, Business Cycles, and the Behavior of Small Manufacturing Firms," Quarterly Journal of Economics, Vol. 109, 309-340.

[19] Hamilton, B.H. (2000): "Does Entrepreneurship Pay? An Empirical Analysis of the Returns to Self-employment." Journal of Political Econnomy, Vol. 108, 604-631.

[20] Herranz, N., S. Krasa, and A. Villamil (2009): "Small Firms in the SSBF," Annals of Finance, Vol. 5, 341-359.

[21] Higson, C., S. Holly and P. Kattuman (2002): "The Cross-sectional Dynamics of the US Business Cycle: 1950-1999," Journal of Economic Dynamics 83 Control, Vol. 26, 1539-1555.

[22] Higson, C., S. Holly, P. Kattuman, and S. Platis (2004): "The Business Cycle, Macroeconomic Shocks and the Cross-section: the Growth of UK Quoted Companies," Economica, Vol. 71, 299-318.

[23] Hopenhayn, H. (1992): "Entry, Exit, and Firm Dynamics in Long Run Equilibrium," Econometrica, Vol. 60, 1127-1150.

[24] Jaimovich, N., and M. Floetotto (2008): "Firm Dynamics, Markup Variations, and the Business Cycle," Journal of Monetary Economics, Vol. 55, 1238-1252.

[25] Kehrig, M. (2011): "The Cyclicality of Productivity Dispersion," Working Paper, Northwestern University.

[26] Khan, A., and J. Thomas (2008): "Idiosyncratic Shocks and the Role of Nonconvexities in Plant and Aggregate Investment Dynamics," Econometrica, Vol. 76, 395-436.

[27] Lee, Y., and T. Mukoyama (2008): "Entry, Exit and Plant-level Dynamics over the Business Cycle," Working Paper, Federal Reserve Bank of Cleveland.

[28] Moskowitz, T.J., and A. Vissing-Jorgensen (2002): "The Returns to Entrepreneurial Investment: A Private Equity Premium Puzzle?" American Economic Review, Vol. 92, 745-778.

[29] Ouyang, M. (2009): "The scarring effect of recessions," Journal of Monetary Economics, Vol. $56,184-199$. 
[30] Quadrini, V. (2009): "Entrepreneurship in Macroeconomics," Annals of Finance, Vol. 5, 295311.

[31] Vereshchagina, G., and H. Hopenhayn (2009): "Risk Taking by Entrepreneurs," American Economic Review, Vol. 99, 1808-1830. 